\title{
Psychosocial and Behavioural Effects of the COVID-19 Pandemic on Children with Autism and their Families: A Systematic Review and Initial Data from a Multinational Online Survey
}

Helene Kreysa ${ }^{1,2^{*}}$, Dana Schneider ${ }^{1,3,4^{*}}$, Andrea E. Kowallik ${ }^{1,2,5,6^{*}}$, Samaneh S. Dastgheib ${ }^{1,2}$, Cem Doğdu ${ }^{1,3}$, Gabriele Kühn ${ }^{5}$, Jenny M. Ruttloff ${ }^{2}$, and Stefan R. Schweinberger ${ }^{1,2}$

${ }^{1}$ Social Potential in Autism Research Unit, Friedrich Schiller University, 07743 Jena, Germany

${ }^{2}$ Department of General Psychology and Cognitive Neuroscience, Friedrich Schiller University Jena, Am Steiger 3/Haus 1, 07743 Jena, Germany

${ }^{3}$ Department of Social Psychology, Friedrich Schiller University Jena, Humboldtstrasse 26, 07743 Jena, Germany

${ }^{4}$ DFG Scientific Network "Understanding Others"

${ }^{5}$ Early Support and Counselling Center Jena, Herbert Feuchte Stiftungsverbund, Dornburger Straße 161, 07743 Jena, Germany

${ }^{6}$ University Hospital for Psychiatry and Psychotherapy, Jena University Hospital, Philosophenweg 3, 07743 Jena, Germany

Note: This manuscript has not been peer-reviewed. The paper has been submitted for publication on February 19, 2021, and is currently under review. 


\begin{abstract}
Background: Since COVID-19 has become pandemic, everyday life has seen dramatic changes affecting individuals, families, and children with and without autism. These entail, among other things, more time at home, digital forms of communication, school closures, and reduced support and intervention. Aim: Here we aim to systematically assess the effects of the pandemic on autistic and neurotypical (NT) children, and pursue a pre-registered hypothesis suggested by initial observations that some children with autism might respond comparatively well to a situation of constrained, predictable, and digital social communication during the pandemic. Methods: We provide a systematic review of current relevant work, including 76 papers selected from a database search until February 1, 2021. We then report survey data from several countries assessing activities, well-being (PedsQL ${ }^{\mathrm{TM}}$ ), and social life in families with autism, and their respective change at various stages of the pandemic. We focus on differences between children with and without autism from within the same families, and on different outcomes for children with high- or low-functioning autism. Results: While children with autism scored lower in emotional and social functioning than their NT siblings, comparable decreases in well-being and increases in anxiety were seen for both groups, compared to before the pandemic. By contrast, decreases in adaptability were significantly more pronounced in autistic than NT children. Preliminary results suggest that changes were comparable for children with high- and low-functional autism overall, but individual differences prevail.
\end{abstract}

Conclusions: Overall, although individual families do report some positive effects of pandemic restrictions, our data give no clear evidence that these generalize across children with autism, or even just to children with high-functioning autism. We discuss significant challenges for children with and without autism that need to be addressed to protect childrens' well-being under pandemic conditions but also point to potential in the present situation that could be used towards social participation and success in older children and young adults with autism.

Key Words: COVID-19; Autism; Systematic Review; Children; Online Survey; Quality of Life ${ }^{*}$ Note: These authors contributed equally.

Running Title: COVID-19 Effects on Children with Autism

Correspondence: Stefan R. Schweinberger, Department of General Psychology and Cognitive Neuroscience, Friedrich Schiller University Jena, Am Steiger 3/Haus 1, 07743 Jena, Germany. stefan.schweinberger@uni-jena.de 


\section{Introduction}

Across the globe, the COVID-19 pandemic has caused a state of crisis, in which local policymakers face the challenge of keeping infection numbers under control, while minimizing negative side effects on mental health and economic prosperity. For children and adolescents with autism ${ }^{[1]}$ and other developmental conditions, many support and intervention programs have either disappeared, or have been restructured to video-based offers that meet the requirements of social distancing. In this paper, we focus on current knowledge regarding the effects of the pandemic on children with autism and their families. In the past 12 months, new scientific papers on this issue have been published at a remarkable pace. Unsurprisingly, not all of these include new data. Several contributions aimed at providing useful tips directed at parents and caregivers of children that consider specific characteristics of autism ${ }^{[2]}$.

One impressive editorial perspective Jefsen et $a^{\left[{ }^{[3]}\right.}$ discussed a survey of more than 60,000 clinical notes on case records from Denmark collected during February and March 2020, as a first step to identify pandemic-related psychopathology in children. The authors hypothesized that children with autism could be particularly vulnerable to distress related to the loss of daily routines, but were careful to explicitly note that their report could be biased in the sense that it focused on pandemic-related psychopathology, whereas the number of individuals that may have actually improved because of pandemic changes was unknown. Keeping in mind limitations of current research in the area, we here (1) provide a systematic review on the current state of knowledge regarding pandemic effects on autistic children and their families, (2) report on a pre-registered study hypothesis that pandemic effects on rated changes in anxiety levels, emotional and functioning, well-being, and coping of school-age children with clinical autism might also be more favourable when compared to neurotypical children (ideally their siblings), which we pursued in an online parent survey conducted in four languages between July and October 2020, and (3) discuss these results and their practical implications, before identifying current gaps in research and future perspectives.

\section{Systematic Review}

On February 1, 2021, we conducted a search on Web of Science, using the search terms “((Covid OR Corona) AND (ASD OR autis*))", for the publication years "2020 OR 2021". We initially identified 107 papers, which were then checked and of which 31 were excluded for 
various reasons (cf. Figure 1 for more details), leaving 76 papers for our systematic review. In an initial step, we categorized papers into one or more of the seven topics we discuss below, all of which were found to be covered by several papers. We then grouped papers into three types of paper, referring to quantitative studies, qualitative studies, or editorials/topical reviews/opinion papers. Of the 76 included papers, 26 were categorized as quantitative studies (cf. Table 1), 8 were categorized as qualitative studies (which could include case reports), and 42 were categorized as opinion papers, topical reviews or editorials. Note that we adopted a rather liberal criterion for categorizing a study as "quantitative", when the study methods were described in some detail, even when only descriptive data (e.g., percentages) were reported. When discussing the surveyed papers, we occasionally refer to studies published before 2020 that are not related to the current pandemic but can be helpful to understand the methods, results, or interpretation of a new study.

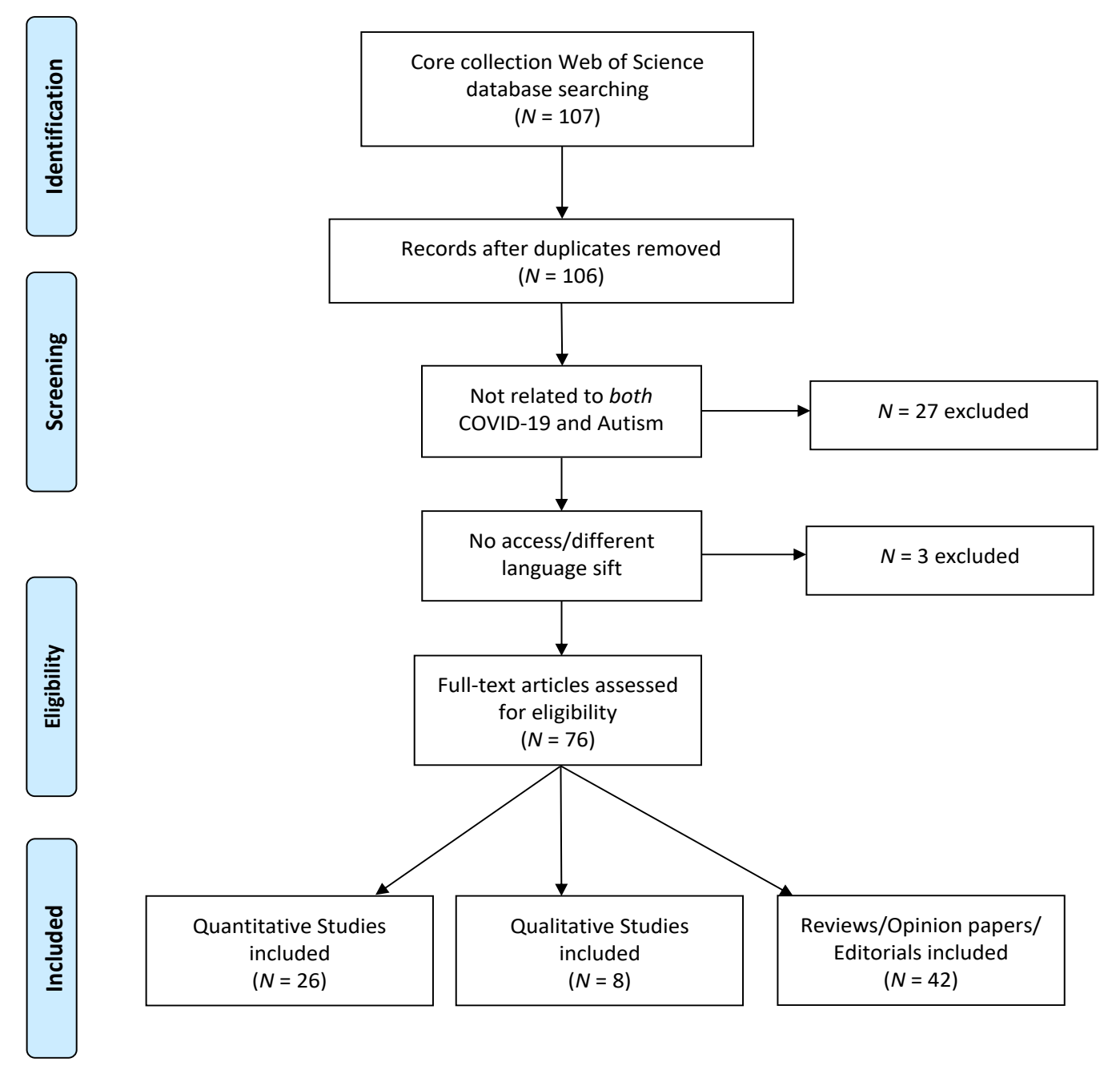


COVID-19 Effects on Children with Autism

Figure 1. Flow chart displaying the search and inclusion process, according to PRISMA group recommendations. 
Table 1. Quantitative Studies Surveyed

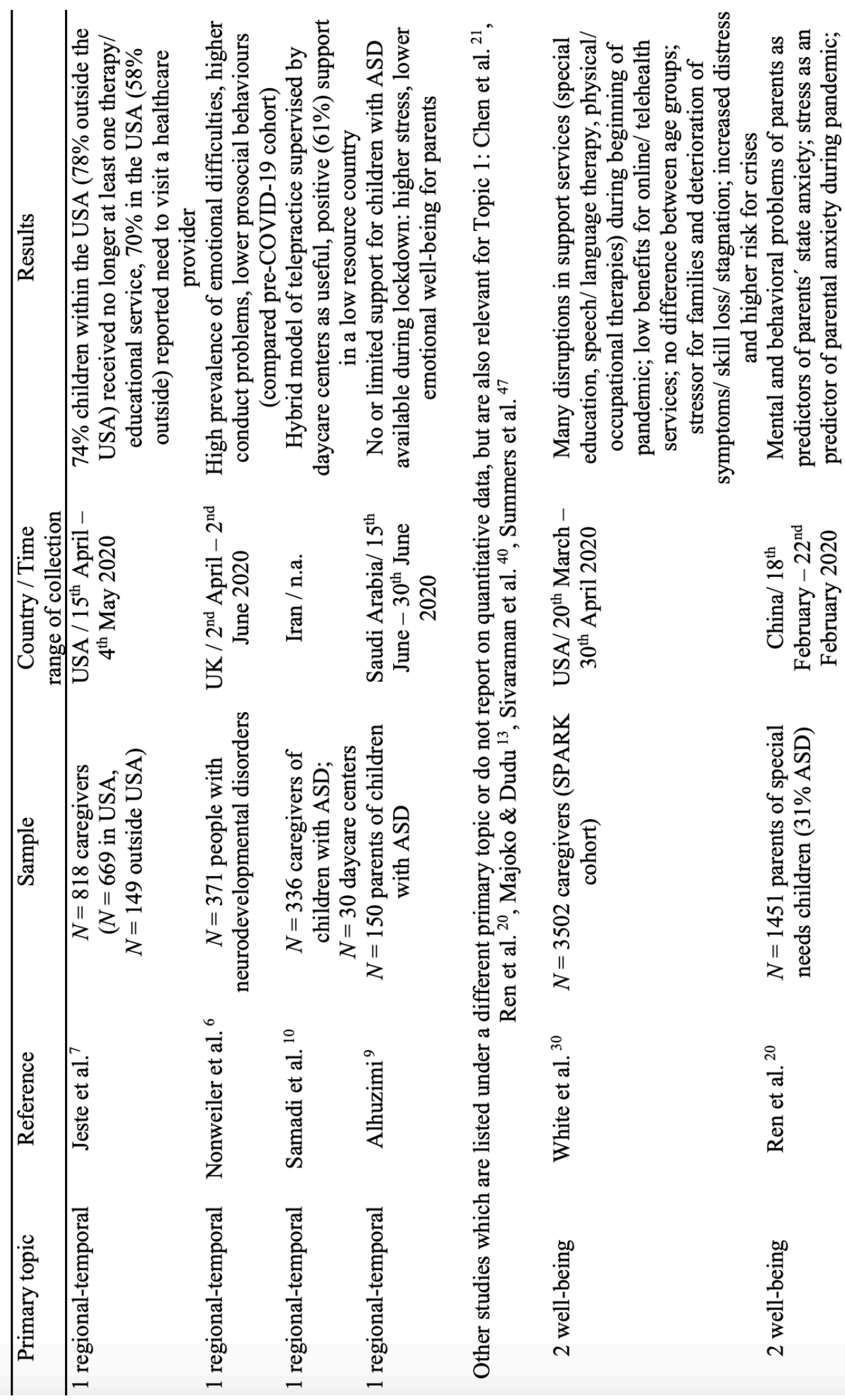


Table 1. Continued
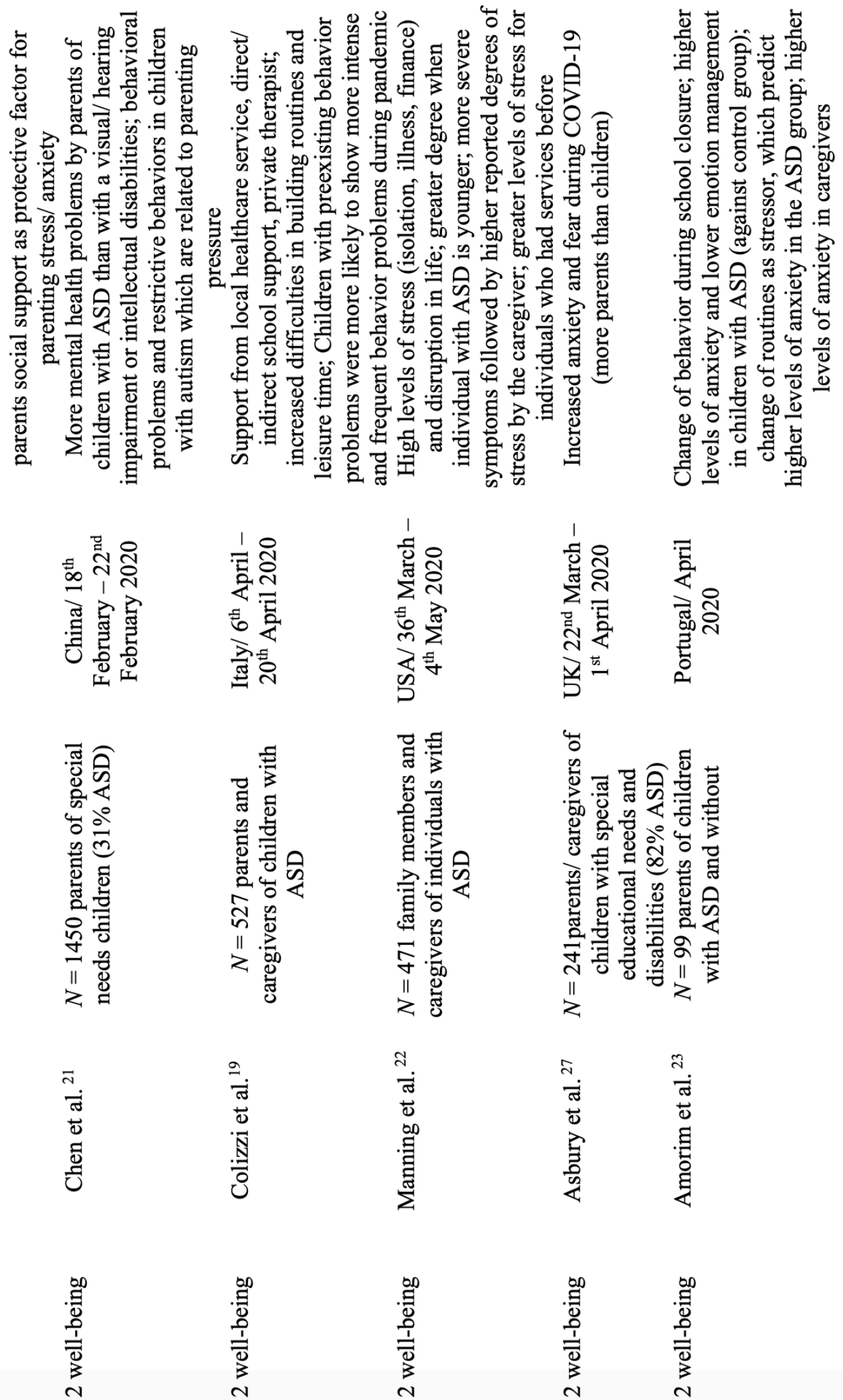
Table 1. Continued
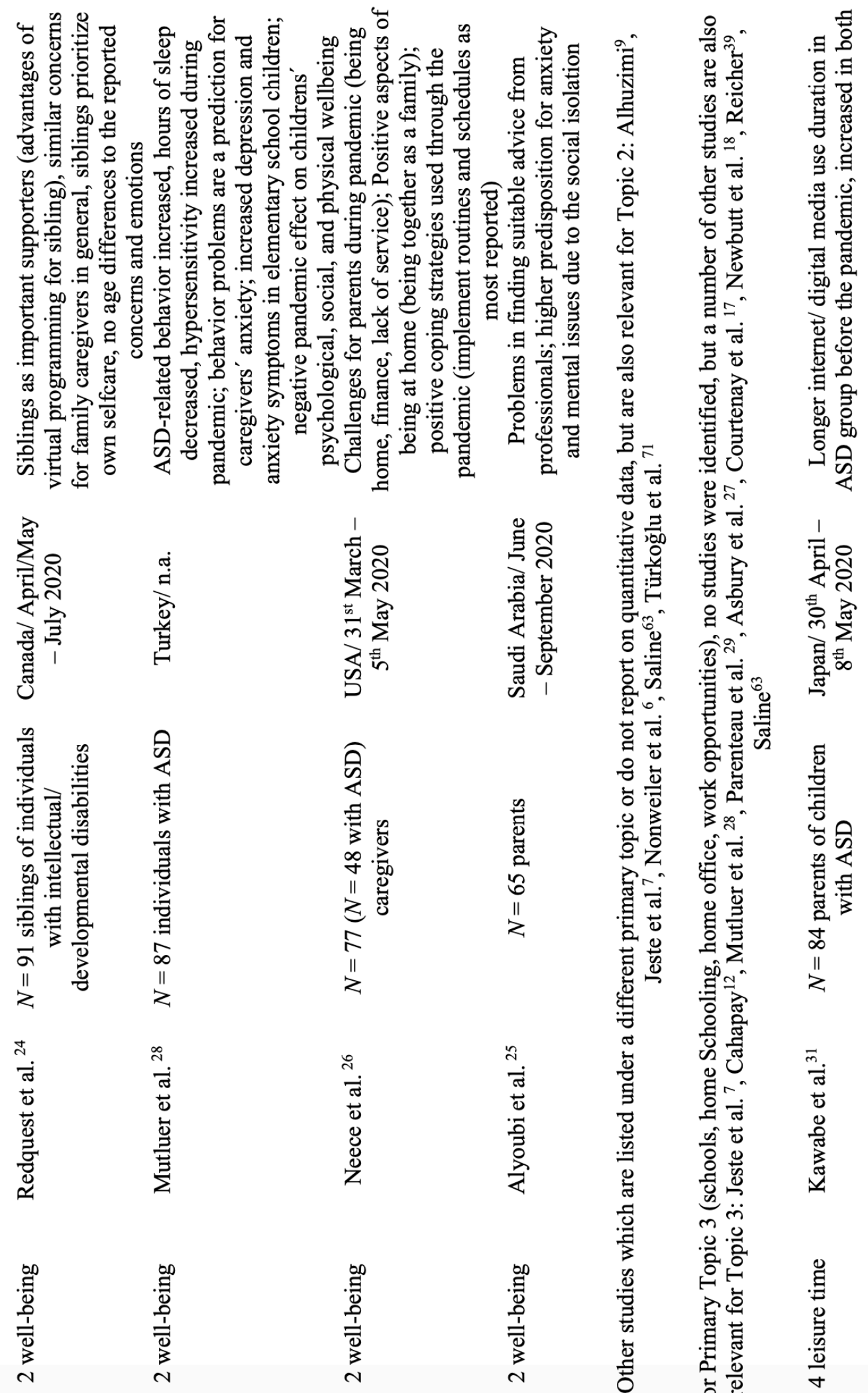

尊

胥:

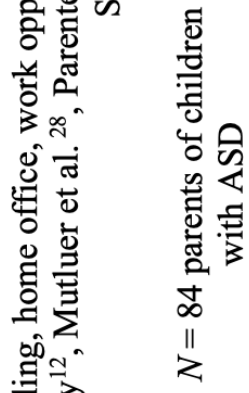

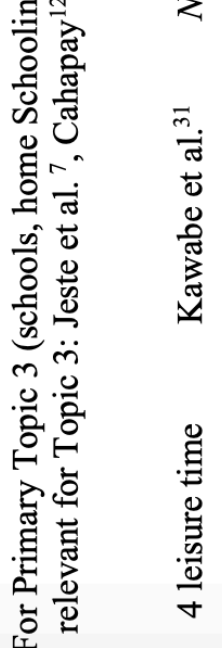


Table 1. Continued
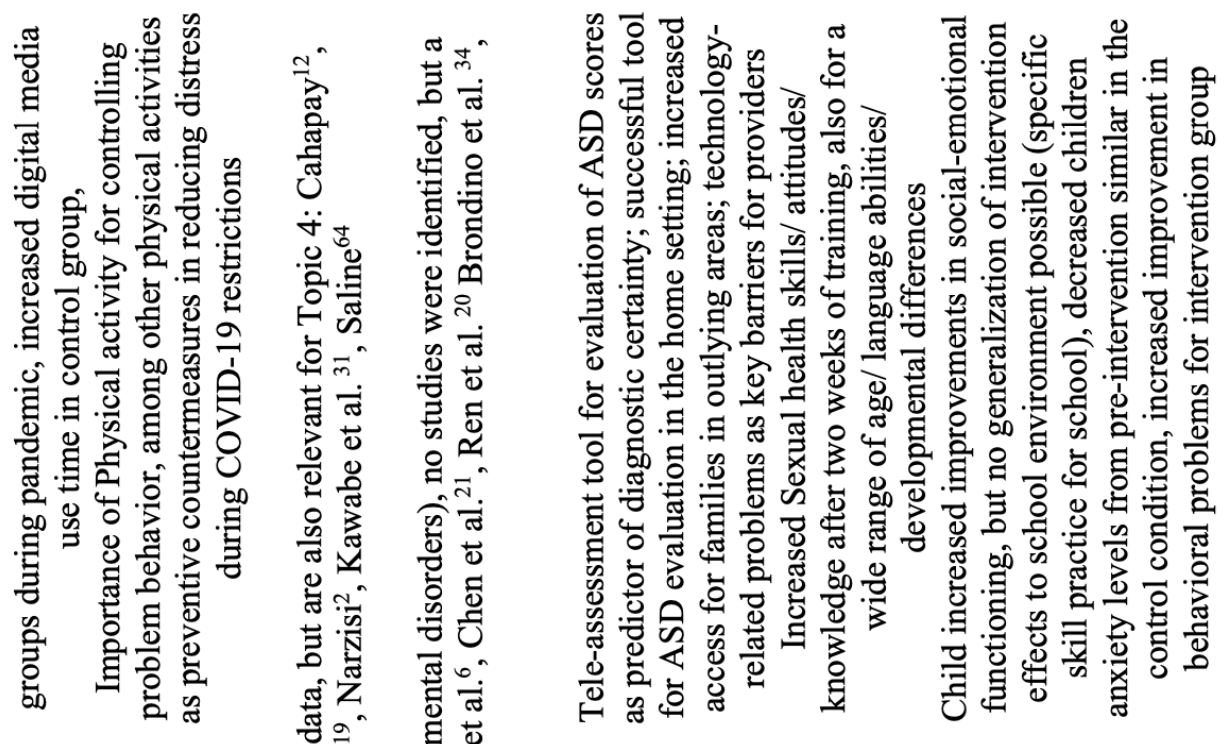

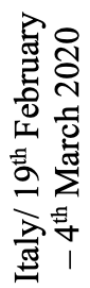

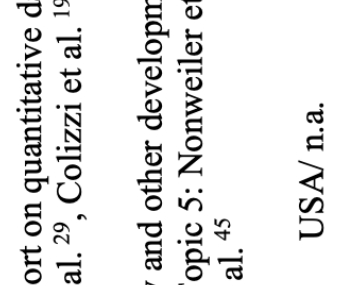

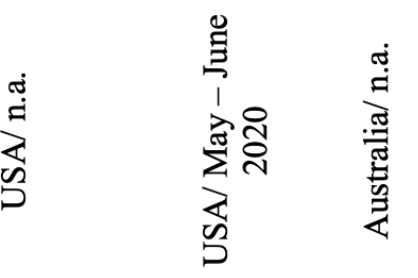

是

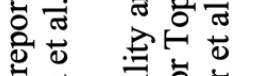

焉

苛 矛芯

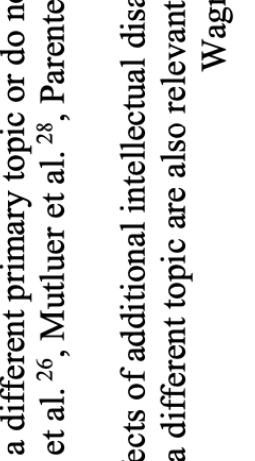
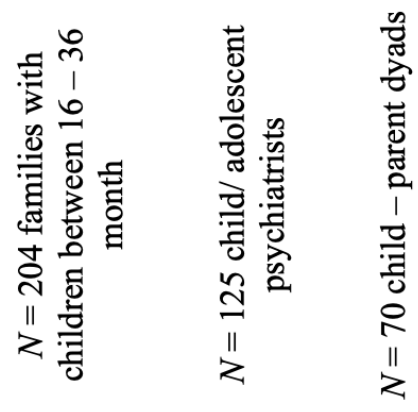

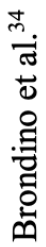

节
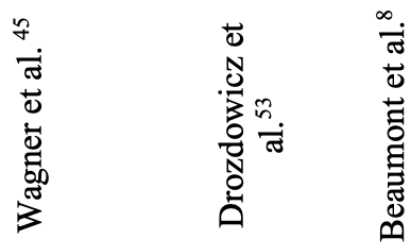

离

ह

密离

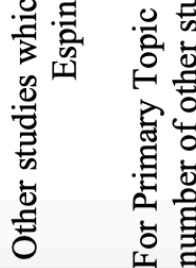

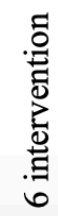

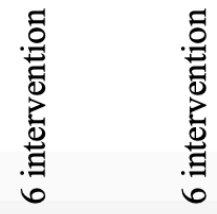


Table 1. Continued

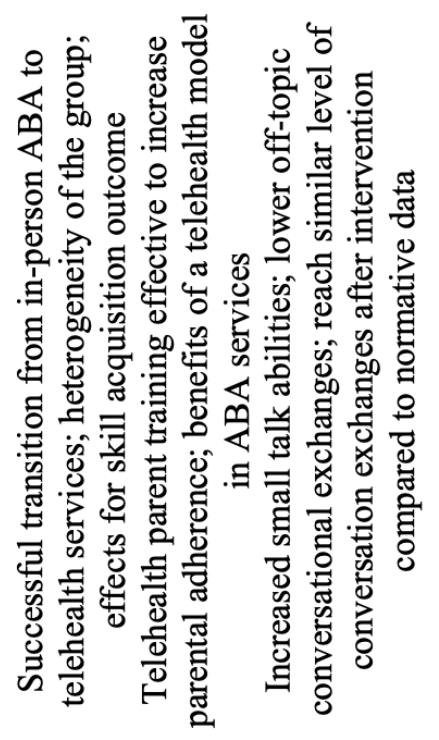

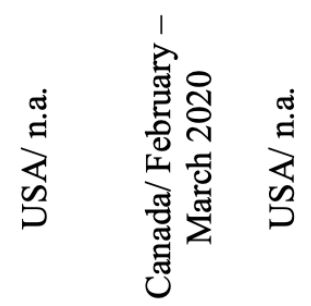

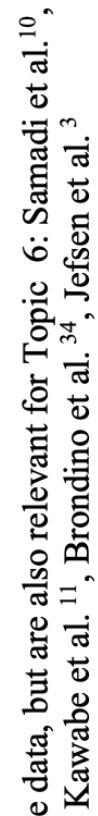
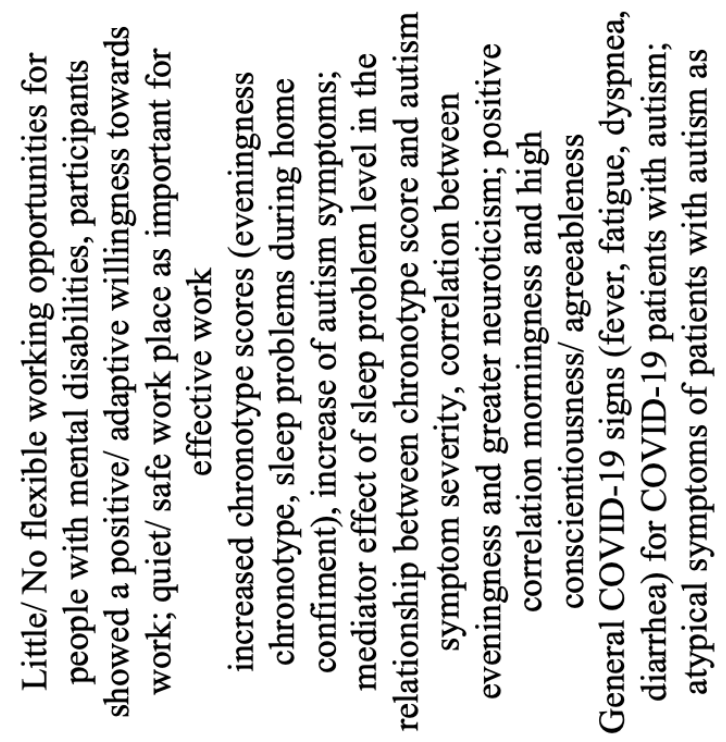

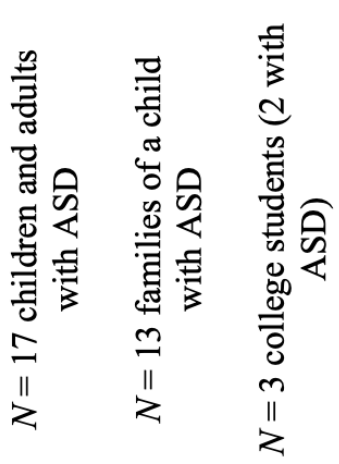

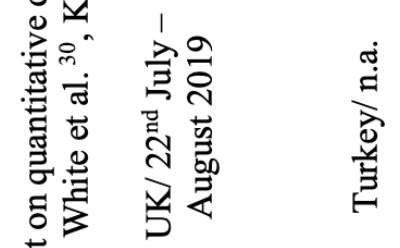

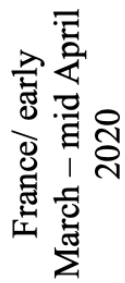

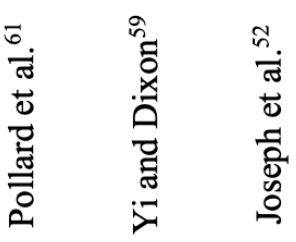

:

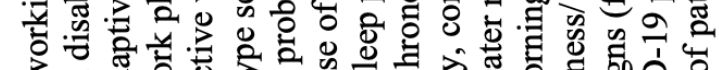

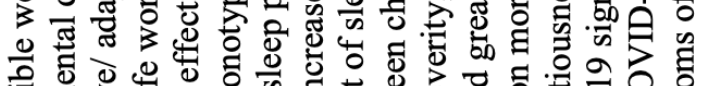

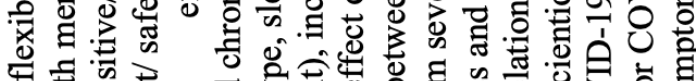

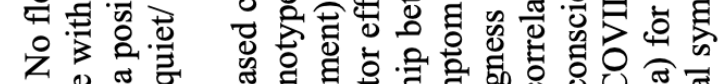

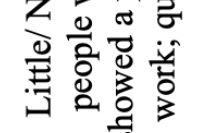

莺

志芯范势

COVID-19 Effects on Children with Autism 
COVID-19 Effects on Children with Autism

Table 1. Continued

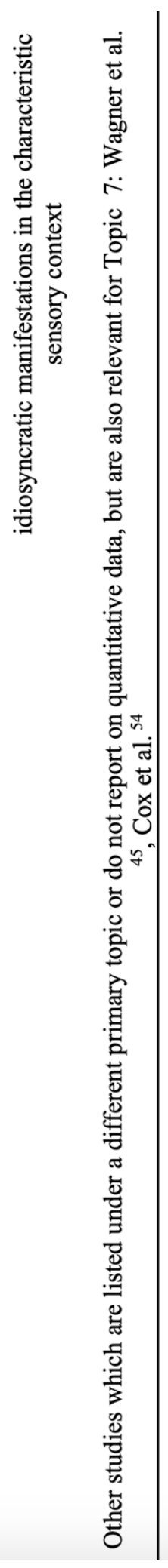




\section{Regional and Temporal Factors}

In different parts of the world, the temporal development of the pandemic and the respective responses by policymakers have been very different. Accordingly, it is important to keep in mind that empirical data need to be seen in this spatio-temporal context, so we listed this information in Table 1 when presenting studies with quantitative data. Pandemic effects on children are likely to differ considerably between a complete lockdown and effective confinement to one's own indoor living space for weeks (as was the case initially in Wuhan, China, and in Italy in early spring 2020), vs. a lighter version of lockdown in a region or phase with moderate infection numbers As examples, initial quantitative evidence related to autism has quickly become available from China ${ }^{[4]}$, Italy ${ }^{[5]}$, the UK ${ }^{[6]}$, the USA ${ }^{[7]}$, Australia ${ }^{[8]}$, Saudi Arabia ${ }^{[9]}$, Iran ${ }^{[10]}$, or Japan $^{[11]}$, and further qualitative research was reported from the Philippines ${ }^{[12]}$, Zimbabwe ${ }^{[13]}$, or Peru $^{[14]}$. Topics were diverse. For instance, a preliminary report from $>3000$ families in China ${ }^{[4]}$ focused on caregivers' well-being and reported that $40-50 \%$ reported anxiety, depression, or stress during the first wave of the pandemic. An early paper from Italy ${ }^{[5]}$ reported on experiences with an initiative in which intervention for autistic children based on applied behaviour analysis (ABA) was almost instantly transferred and implemented by parents in the complete lockdown; parents were trained remotely via a telehealth system. Regarding country of origin, our survey reveals substantial numbers of contributions from the USA and the UK, whereas relevant reports from many countries (including Germany) and even world regions are currently missing (cf. Figure 2). With one partial exception ${ }^{[7]}$, there is currently a lack of studies that include data from more than one country or include a longitudinal analysis of pandemic effects at various pandemic phases. The interested reader is also directed to the contribution by Amaral et al ${ }^{[83]}$, which integrates a number of short comments and perspectives about the situation until June 2020, from editorial board members and global senior leaders of the International Society for Autism Research (INSAR).

\section{Well-being of Parents, Caregivers, and Individuals with Autism}

Difficulty in dealing with change is an important diagnostic criterion for autism spectrum disorders ${ }^{[15]}$. So, it seems natural that the rapid changes brought about by the pandemic have prompted numerous authors to address the well-being of families with autistic family members. Theoretically discussing the topic, Bellomo et $a^{[16]}$ pointed out the risks of delayed ASD diagnosis and comorbidities as well as reduced numbers and quality of therapy options. The 
main concerns were globally poorer health outcomes in the future. Courtenay and Perera [17] and Newbutt et al ${ }^{[18]}$ focussed on the limits of children with ASD understanding the changes and restrictions in daily activities, leading to mental stress, anxiety, and behavioural problems. Courtenay and Perera ${ }^{[17]}$ also pointed out the increased likelihood of exploitation and domestic abuse, as children are no longer protected by their usual communities. Their key message was to make and keep services available, to improve quality of life and wellbeing.

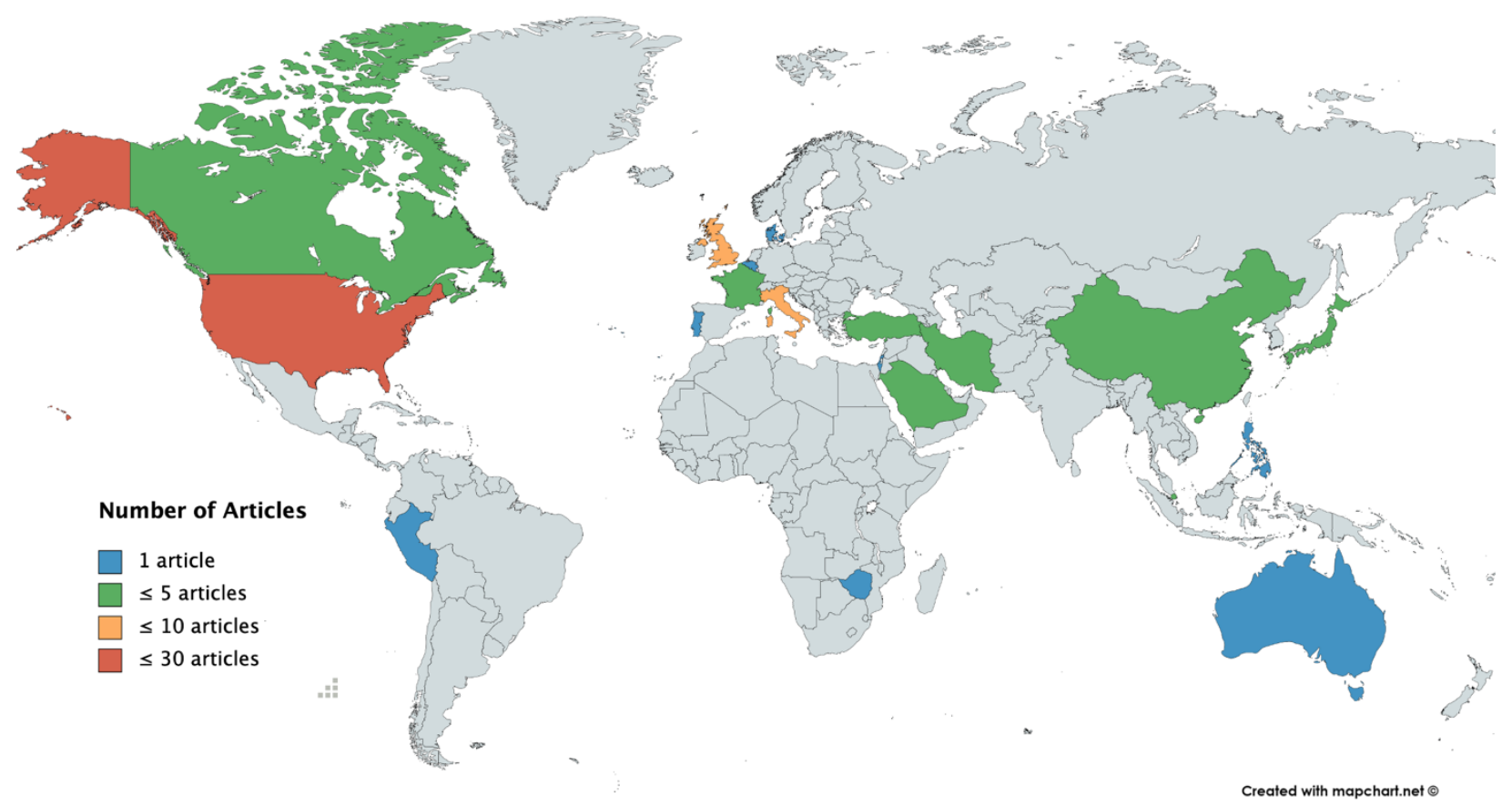

Figure 2. Countries of origin of the 76 papers included in the systematic review (cf. Figure 1), colourcoded by the number of contributions on a World Map (https://mapchart.net/world.html, free online tool). In detail, contributions came from 19 countries, with information per country on the total number of papers/the $n$ of quantitative studies/ $n$ qualitative studies, and $n$ either topical reviews, editorials or opinion papers given in this order: Australia (1/1/0/0), Belgium (1/0/1/0), Canada (5/2/0/3), China (3/2/0/1), Denmark (1/0/0/1), France (4/1/0/3), Iran (2/1/0/1), Israel (1/0/0/1), Italy (7/2/1/3), Japan (2/1/0/1), the Philippines (1/0/1/0), Portugal (1/1/0/0), Saudi Arabia (2/2/0/0), Singapore (2/0/0/2), Turkey (5/2/1/2), UK $(10 / 3 / 2 / 5)$, USA (29/8/1/19), and Zimbabwe (1/0/1/0). Note: Map data are for 79 papers, including 3 further papers (one from Peru, one from the USA, and one from Italy) which were excluded from the systematic review although they were topically relevant, either because they were written in a different language, or because we had no access to the full text.

The favoured empirical approaches to gain insight into family well-being were parent surveys and interviews. In their self-reports, the majority reported the phase of the first lockdown in Europe as a challenging period ${ }^{[19]}$. Parents described themselves as highly stressed ${ }^{[20,21,22]}$ and impaired in their emotional well-being ${ }^{[9]}$. Compared to parents without autistic children, 
caregivers of autistic children reported higher anxiety levels ${ }^{[23]}$. Factors like the younger age of children with ASD and higher severity of ASD were associated with greater parental stress ${ }^{[22]}$. When adult siblings served as caregivers for their siblings with intellectual disability, the majority also expressed worrying about the future, stress and guilt ${ }^{[24]}$. Alyoubi et al ${ }^{[25]}$ also found a correlation between access to the appropriate help on the one hand, and less perceived guilt as well as more confidence of parents on the other hand. However, some positive aspects of the pandemic were also reported, including improved family relationships or being more present and peaceful ${ }^{[26}$ see also 27$]$.

For their affected children, parents reported changes in behaviour, poorer emotion regulation/management, and higher levels of anxiety, especially if routines were distorted, and compared to fewer ${ }^{[23]}$ or less profound changes in the control group ${ }^{[6]}$. Further changes in behaviour included an increase in ASD core symptoms such as stereotypes ${ }^{[3]}$, but also an increase in aggression, hypersensitivity, sleep and appetite alterations ${ }^{[28]}$ and decreased social skills ${ }^{[29]}$ or fewer prosocial behaviours ${ }^{[6]}$.

To summarise, the concerns about the pandemic raised by practitioners and scientists are supported by the surveys conducted with affected families. As routines and help services were disrupted, the pandemic has put even more pressure on families with autistic family members, resulting in reduced well-being in autistic children and their caregivers ${ }^{[30]}$. This rise in stress and anxiety levels could lead to a general increase in mental disorders in the affected families.

\section{Schools, Home Schooling, Home Office, and Work Opportunities}

School closures and distance learning are a new global phenomenon resulting from the need to slow down virus spread. To meet the need for routines, experts advised affected families to maintain dedicated time slots for school work and to connect regularly with classmates and teachers ${ }^{[2,31]}$. Stennhoff et al ${ }^{[32]}$ further developed detailed guidelines on how teachers and parents can support students' learning, e.g., by providing a well-structured learning environment and clear instructions.

In the course of the pandemic, about three-quarters of children initially lost at least one of their educational services, and about half of the children received at least one service through tele-education, as suggested by data obtained in April and May 2020 from the USA and beyond ${ }^{[7]}$. Tele-education was rated to be helpful to some extent by most parents. Those who received 
more tele-education rated such services as more helpful. Parents wished for more frequent teleeducation, a continuation of the previously provided services, and more in-person services. Qualitative research from Zimbabwe and the Philippines found that families needed to adjust their routines, implemented more diverse learning environments (e.g., educational games), but also gave some parents the opportunity to impose cultural gender roles in home education routines ${ }^{[12,13]}$.

\section{Leisure Time, Physical Activities, and Internet and Social Media Use}

In many countries, recreational activities have been restricted as protective measures against the global pandemic spread. As children with ASD are more prone to being overweight and having a sedentary lifestyle, the restrictions and online learning environments likely added to these conditions ${ }^{[21]}$. Thus, detailed advice was provided to promote home-based physical activity ${ }^{[33]}$. Another line of advice also suggested structuring leisure time to some extent, e.g., by assigning different rooms for different activities, establishing rules for gaming and using the internet, or creating family playtimes ${ }^{[2,31]}$

The difficulty of being at home all the time was indeed reported as the primary challenge by parents in the USA ${ }^{[26]}$. Implemented daily schedules, optimized for the child's needs, were reported as beneficial ${ }^{[29]}$. Parents had positive opinions on physical activities (e.g., health, social and psychological benefits), but barriers like having to work, security concerns, or insufficient online or tele-education (reported by parents as a lack in their own knowledge) made the implementation of physical activities difficult. In a study from Japan, internet use in children and adolescents increased during the pandemic throughout ${ }^{[11]}$. Although the control group had lower pre-pandemic internet or digital media use (median $=2$ hours) than the ASD group (median $=3$ hours), surprisingly, the increase was even more pronounced in the control than the ASD group (2 hours vs. 1.25 hours). Brondino et al ${ }^{[34]}$ reported results for young adults with severe ASD treated in a daycare center in which all structures were maintained but adapted to the current situation (e.g., swimming and contact sports were substituted by daily trekking). Of relevance, these authors reported no significant aggravation of problematic behaviour, compared to pre-pandemic times. 


\section{Pandemic Effects on Individuals with Autism: Moderating Effects of Additional Intellectual Disability and Other Developmental Disorders}

Several authors emphasize that pandemic disruptions of daily routines and predictability can be challenging for individuals with autism. Adverse effects could be particularly pronounced for children with intellectual disabilities, who might have difficulty understanding the context of these changes ${ }^{[35]}$. Conversely, it remains possible that some high-functioning children with autism could even respond positively to the reduction of direct face-to-face social interaction. In many ways, digital social communication and telehealth systems may promote a more predictable and controlled mode of interaction, thus resonating well with autistic individuals' tendency to "systemize," i.e., their drive to predict, control or construct systems ${ }^{[36]}$. This could explain why technology-based interventions may be promising for people with autism (for reviews, see Pennisi et al., 2016; Kowallik \& Schweinberger, 2019; see also next section) ${ }^{[37,38]}$. In school contexts, this is well illustrated by case reports of two boys with high-functional autism ${ }^{\text {[39] }}$. These boys enjoyed, and excelled in, distance learning. Reicher speculates that this may be because eliminating the demands of the "hidden curriculum" of subtle rules for classroom behaviour allows autistic children to use their cognitive and emotional resources for the formal curriculum, with positive effects both on performance and life quality. In the context of the pandemic, quantitative evidence regarding a modulating effect of intellectual functioning on the benefits of telehealth are largely missing, or indirect. White et al ${ }^{[30]}$, in a large US dataset of 3502 parent surveys conducted between March 20 and April 29, 2020, discuss evaluations of telehealth offers by parents. One of their important findings was that reported benefits from online or telehealth offers increased with the age of the recipients, particularly for special education and mental health services, and were minimal for pre-school children.

\section{Intervention}

\section{Telehealth}

A need for healthcare support, in-home or center-based, was most commonly reported by parents during lockdown ${ }^{[19]}$. To understand the changes, comply, and stay safe, several interventions were presented to help autistic people comprehend the pandemic and precautionary measures. For example, this was realized through cartoons ${ }^{[31]}$ and social stories that helped visualize more abstract facts. One intervention study aimed to make autistic children 
comfortable wearing a mask by modeling and graduated exposure, descriptively increasing mask-wearing duration ${ }^{[40]}$.

Periods of home-confinement have rapidly given rise to remote forms of healthcare interventions and trainings ${ }^{[41,42]}$. These shifts to telehealth offered unique advantages, like providing new insights into childrens' lives or greater flexibility in scheduling meetings. However, it also has disadvantages, like lacking traditional rapport-building activities and visualizations, distractions in the home-environment, or amplifying autistic communication difficulties ${ }^{[43]}$. Entirely telemedical approaches to monitor infants at risk for ASD ${ }^{[44]}$, as well as online tools (TELE-ASD-PEDS) ${ }^{[45]}$ or complete working models for ASD diagnosis and intervention planning, were created ${ }^{[46,47]}$. A good implementation of those new workflows, including telehealth, could lead to better use of professional resources, improved access especially in rural areas, shorter waiting periods, and higher care quality ${ }^{[48,49]}$. Nevertheless, given the circumstances, even bestpractice telehealth did not always reach the goal of improvement and left parents and care teams with open questions on how to proceed ${ }^{[50]}$. Loman et $a^{[51]}$ discuss in detail challenges and practical recommendations that are involved in both diagnosis and intervention in autism. Although the gold standard ADOS-2 cannot be administered validly in full without face-to-face interaction, these authors make useful recommendations for best practice under conditions of social distancing.

Beaumont et al ${ }^{[8]}$ adapted an existing computer game-based social skills program for autistic children to a caregiver-supported version. This adaptation improved social skills and problem behaviour in the treatment group $(\mathrm{N}=35)$ compared to a control group $(\mathrm{N}=35)$ without training. A remote audio coaching for young adults with intellectual disabilities $(N=3)$ seemed to effectively teach small talk skills ${ }^{[52]}$.

Child and adolescent psychiatry practitioners in the USA were also targeted by an ASDspecific training on sexual health that consisted of video clips and video-conference meetings (like Zoom). This training significantly increased practitioners' skills, knowledge, and positive attitudes, while having a broad countrywide outreach ${ }^{[53]}$.

\section{Cognitive and Behavioural Methods}

There has been an ethical discussion about ABA providers and the decision-making process for the needs of in-person treatments. Cox et al ${ }^{[54]}$ argued that the risk of continued in-person treatment outweighs possible benefits for many clients and that temporal suspension of services 
or telehealth may be the preferred option for most clients. Reviewing the scarce data base on telehealth, Schlietz and Wacker ${ }^{[55]}$ suggested telehealth to be equally effective as in-person ABA. Others argued for maintaining 1:1 treatment as far as possible, and in-person treatments when needed ${ }^{[56]}$ or even keeping the physical setting where possible ${ }^{[57]}$ while implementing adequate safety procedures ${ }^{[58]}$. Yi and Dixon ${ }^{[59]}$ provide details on implementations of their telehealth model for ABA, and Nicolson et al ${ }^{[60]}$ added the clients' perspectives to the decisionmaking process by providing a caregiver interview to assess demand for changes in frequency or setting.

Espinosa et al ${ }^{[5]}$ set up a very intense ABA-based telehealth intervention programme for parents, teaching them to implement daily structures, choosing appropriate activities and ABAspecific interventions (e.g., discrete trial teaching), setting up a reinforcement system. Pollard et $a^{\left[{ }^{[61]}\right.}$ showed that, given the right circumstances, telehealth can be as efficient as in-person treatment. Specifically, when the form of instruction (parent-instructed, telehealth parentassisted, or telehealth directly with the practitioner) was chosen according to the child's abilities and the number of training hours was maintained, most children continued to benefit from ABA training.

Another line of suggested training is based on Acceptance and Commitment Therapy (ACT). For example, the detailed guidelines by Szabo et al ${ }^{[62]}$ promote parents' use of schedules and routines, family values and norms, and positive reinforcement by suggesting specific values-based exercises. The 5 C's method (self-control, compassion, collaboration, consistency, celebration) for supporting families with alternative-learning children was also discussed in the light of the current pandemic ${ }^{[63]}$. Tarbox et al ${ }^{[64]}$ fitted well-known ACT exercises to the pandemic situation to implement them into an ABA-based therapy framework to help children cope with the changes.

Kalvin et al ${ }^{[43]}$ suggested modifications for a telehealth-based cognitive behavioural training for anxiety in children with ASD. They found specific changes in anxiety, depending on the type of anxiety (e.g. decreases in social anxiety, increases in fears of contamination or family safety) that made re-evaluations of goals and anxiety hierarchies and subsequently new exposure exercises necessary. They argued for letting parents provide developmentally appropriate information about COVID-19 while also setting realistic expectations with the children. 
Overall, the new situation brought big challenges and a high risk of leaving a vulnerable population behind, while at the same time giving rise to the use of technology that might provide helpful additional resources in the post-pandemic world.

\section{Brief summary of reviewed work}

In the systematic review, we were able to survey substantial initial data collected across the globe and published within the first year of the pandemic. A large portion of the work was relevant to well-being and intervention, but data are also beginning to permit regional-temporal comparisons, and to inform about schooling or leisure time changes. We take away that children with autism tended to show less adequate emotion regulation and higher stress levels, particularly when daily routines were distorted. An increase in ASD core symptoms (i.e., stereotypical behaviours and decreased social skills) as well as an increase in aggression, hypersensitivity, sleep and appetite alterations were reported. Despite that, caregivers' well-being has been affected by anxiety, depression, or stress as routines and help services, schooling, and work opportunities were no longer available, or were available only in limited alternative forms. To meet the special routines required for individuals with ASDs, various studies made very clear that dedicated time slots for school/work and leisure time should be maintained given altered environments (e.g., more time at home, tele-education, educational games, physical activities at home, family playtimes, etc.). This was reported to buffer against increases in ASD core symptoms. Interestingly to note, benefits from online or telehealth offers appeared to increase with the recipients' age, particularly for special education and mental health services, and were low for pre-school children. Digital internet or media use seemed less increased in children and adolescents with ASD compared to control individuals, despite higher levels of pre-pandemic internet use. Many contributions related to diagnosis and intervention pointed out that the COVID-19 pandemic brings a high risk of leaving vulnerable individuals with ASD behind. At the same time, a huge push was observed in terms of telehealth implementations when it comes to explaining new hygiene practices using cartoons and social stories, tele-diagnostic instruments even for children under 36 months of age, telehealth set-ups for established cognitive and behavioural therapies (e.g., ABA and ACT) as well as social skills programs (e.g., Junior Detective Training Program). Positive aspects of the pandemic were sparsely reported but included improved family relationships or being more present and peaceful. 


\section{Online Survey}

In our online parental survey, we focussed on assessing activities, well-being, and social life in families with autism, as well as changes at various stages of the pandemic. We aimed to compare pandemic effects on children with and without autism, ideally from within the same families. We collected data n summer 2020, after the first wave of infections in each country, when infection numbers were relatively low but respondents presumably had a relatively fresh representation of their experiences during the first wave. Initially, we had also planned to compare data across several countries and four languages to assess similarities and differences across different world regions. However, because our final sample was too small to permit comparisons across world regions with sufficient statistical power, we integrated the data across the four languages in the present report.

Our online survey (https://aspredicted.org/us3py.pdf) was preregistered on June 16, 2020. It was approved by the Ethics committee of the Ethical Commission of the Faculty of Social and Behavioural Sciences of the Friedrich Schiller University Jena (FSV 20/025). An initial power analysis using GPower $3.1^{[65]}$ suggested that a minimum sample size of 53 per group (autistic vs. neurotypical) would be required in order to identify a medium-size effect of $d$ $=0.5$ for a comparison between two groups (nonparametric Wilcoxon-Mann-Whitney t-test, onetailed, alpha set to .05 , power of .80). We stopped data collection after ten weeks, as infection rates in all countries of relevance at that time were significantly increasing, suggesting that the next infection-wave was coming (i.e., September 22, 2020, 7-day incidence per 100,000 inhabitants: Germany: 1,771; Iran: 3,120; Turkey: 1,672; UK: 4,189; according to interactive trashboard data from John Hopkins University, see https://systems.jhu.edu/tracking-covid-19/). We ended data collection with 70 surveys in total. For this reason, some of the analyses presented in the following may be based on low statistical power and should therefore be interpreted as exploratory, and with due caution. Nonetheless, in several aspects, they extend beyond what has been reported in the literature on ASD and COVID-19 so far, and thus are worthy of consideration.

\section{Methods}

Four parallel versions of an online survey were generated using SoSci Survey ${ }^{[66]}$ and made available to users via www.soscisurvey.de. The four versions differed only in the survey 
language: English, German, Turkish and Persian (Farsi), each translated by a native/ fluent speaker of the respective language. The English version is provided in the supplemental material, and all four language versions are available via this link at osf.io/sm3ze/. The survey was online from July 16 to October 31, with the last dataset entered on September 22, 2020. During this time, 70 surveys were completed by parents of school-age children and adolescents with a clinical diagnosis of ASD in seven countries (German version, $n=37$ : Germany and Austria; Persian version, $n=15$ : Iran; Turkish version, $n=13$ : Turkey; English version, $n=5$ : Australia, USA, UK). Participants were recruited through professional networks and postings in social media.

A closer look at the data revealed that only 57 of the children and adolescents actually had a clear and confirmed clinical diagnosis of ASD. These children (14 female, 25\%; 40 male, $70 \%, 3$ undisclosed/diverse) varied considerably both in age (5-20 years, $M=11.09$ years, $S D=$ 3.97 ) and in level of required support (3 - very little, 26 - some, 21 - substantial, 7 - very substantial). For comparison purposes, parents were also asked to provide information on one neurotypical child they were in frequent contact with. This provided data for 53 neurotypical children (23 female, $43 \%$; 29 male, $55 \%$; 1 undisclosed/diverse; age 0-25 years, $M=10.0, S D$ $=4.87$ ).

For a first set of analyses, the children and adolescents with autism were collapsed into a (comparatively) high-functional subgroup (requiring very little or some support; $n=29$; AQ-10: $M=7.21, S D=2.21$ ) and a low-functional subgroup (requiring substantial or very substantial support; $n=28$; AQ-10: $M=8.11, S D=1.47)$.

Please note that not all parent reports contained full data for both one child with confirmed autism and a clearly neurotypical comparison child. A second set of analyses therefore focused on comparisons only within the 43 reports that comprised both one child with a confirmed autism diagnosis (AQ-10: $M=7.65, S D=1.91 ; 12$ female, $28 \%$; 30 male, $70 \% ; 1$ undisclosed/diverse, $2 \%$; age: $M=10.78, S D=4.07$ ) and one control child that was indicated as uncontroversially neurotypical $(A Q-10: M=1.67, S D=1.84 ; 20$ female, $48 \%$; age: $M=10.24$, $S D=5.16)$. A t-test confirmed that this novel form of familial reporting actually achieved a rather good age-match between the two groups $(t(40)=0.862, p=.394, n=41$ per group because age data were not provided for 2 children with and one child without autism, affecting age data for 2/43 pairs). We should add that in all analyses that compare autistic and neurotypical children, 
we obtained similar results when using the entire dataset (thus having slightly larger samples at the expense of losing family matching).

Among other information (for a detailed description, please refer to the Supplemental Materials), the survey assessed demographic information about the responding parent, the children with and without autism, the rest of the family, and the child's autism diagnosis (using the $A Q-10$ child version) ${ }^{[67]}$. We also asked about living conditions, local pandemic restrictions, and the parent's personal views on the pandemic. For both the child with autism and the neurotypical control child, parents indicated how much time per day they spent on a variety of activities (e.g., computer games, online learning, sleeping, and playing outside) before the pandemic, at the peak of the first wave, and at the time of answering (summer 2020, which was typically during low incidence rates). In addition, they reported on how well children complied with hygiene rules and filled in the PedsQL TM General Well-Being Scale - Pediatric Quality of Life Inventory ${ }^{\mathrm{TM}}$ General Well-Being Scale (PedsQL, Mapi Research Trust) ${ }^{[68]}$ in English, German, Turkish, or Farsi for Iran (contact information and permission to use for all four language versions: Mapi Research Trust, Lyon, France, https://eprovide.mapi-trust.org). Finally, parents were given the opportunity to mention specific problems, stressors, and support and to comment on the situation in general.

\section{Results}

We compared siblings with and without autism from the same families regarding scores on the PedsQL ${ }^{\mathrm{TM}}$ dimensions emotional functioning and social functioning. These scores range from 0 to 100 , with higher scores representing higher levels of functioning. Children with autism showed lower levels of both emotional functioning $(M=49.3, S D=19.6,10-95, n=43)$ and social functioning $(M=34.5, S D=21.7$, range $0-85)$ than their siblings without autism (emotional: $M=65.0, S D=17.0$, range 25-100, $n=43$; $t(42)=-4.702, p<.001$; social: $M=$ $76.5, S D=23.13$, range 10-100; $t(42)=-9.638, p<.001$ ). Similarly, considering all children with autism, the high-functional children $(n=29)$ showed higher levels of emotional $(M=57.24, S D=$ 19.67; range 20-100) and social functioning $(M=42.76, S D=23.78$, range 10-100) than lowfunctional children $(n=28$, emotional: $M=45.89, S D=19.1$, range 10-100; $t(55)=2.209, p=$ .031 ; social: $M=29.11, S D=20.82$, range $0-85 ; t(54.5)=2.308, p=.025)$. In all groups of children, the range of responses was considerable. 
Siblings with and without autism did not differ significantly in their reported response to, and compliance with, the hygiene recommendations regarding physical distancing, hand washing, and using disinfectant (all ps > .3), assessed on a 3-point scale from negative (-1) to positive (1). However, children with autism responded less positively to wearing a face mask ( $M$ $=0.0, S D=0.9)$ than their neurotypical siblings $(M=0.35, S D=0.77 ; t(4239)=-2.303, p=.027$, $n=43$ ). Considering all children with autism, low-functional children were reported to respond negatively to face masks $(M=-0.21, S D=0.92, n=28)$, while the response of high-functional children was more positive $(M=0.21, S D=0.86, n=29 ; t(55)=1.788, p=.079)$. Interestingly, all other means for hygiene behaviours were positive in all groups of children, suggesting that overall most children comply with hygiene recommendations most of the time.

At the time of the parents' reports, both autistic and neurotypical children showed a decrease in general well-being and social behaviour and increased overall anxiety compared to the time before the pandemic. These measures were assessed using a 5-point scale from much increased (2) to much decreased (-2). An overview is provided in Table 2, which first reveals changes for high- and low-functional children with autism, and second for autistic vs. neurotypical children from within the same families. Please note that comparisons with small sample sizes may be affected by low statistical power. Nevertheless, autistic children showed a much larger decrease $(M=-0.74, S D=1.18)$ than their neurotypical siblings $(M=-0.19, S D=$ $0.91 ; t(42)=-2.439, p=.019 ; n=43)$ in adaptation abilities. This pattern was numerically similar in the comparison within autistic children, potentially indicating greater declines in adaptation abilities for low-functional children than high-functional children.

Finally, we asked about changes compared to the time before the pandemic at the level of entire families with at least one child with autism $(n=57)$. This measure, which was constructed to score from -2 to 2 , as above, revealed both negative and positive aspects of the pandemic: On the one hand, the general stress level $(M=0.82, S D=1.23)$ and frequency of family conflicts $(M=0.61, S D=1.0$ were both reported to have increased considerably (simple t-tests against zero: $t(56)=5.076, p<.001$, and $t(56)=4.656, p<.001$, respectively). On the other hand, marked increases were also reported regarding the amount of time spent together $(M=0.93, S D=1.12 ; t(56)=6.292, p<.001)$ and emotional closeness $(M=0.54, S D=1.04$; $t(56)=3.962, p<.001)$. Again, parents used the entire scale from -2 to +2 to report on these aspects, suggesting a wide variability in how different families experienced and/or responded to the changes. 
Table 2. Overview of mean changes in quality of life and function compared to the time before the pandemic (SD in brackets).

\begin{tabular}{|c|c|c|c|c|c|c|}
\hline & & $\begin{array}{c}\text { General } \\
\text { well- } \\
\text { being }\end{array}$ & $\begin{array}{c}\text { Adaptation } \\
\text { abilities }\end{array}$ & $\begin{array}{c}\text { Overall } \\
\text { anxiety levels }\end{array}$ & $\begin{array}{l}\text { Emotional } \\
\text { reactions }\end{array}$ & $\begin{array}{c}\text { Social } \\
\text { behaviour }\end{array}$ \\
\hline \multirow{2}{*}{$\begin{array}{l}\text { All autistic } \\
\text { children with } \\
\text { confirmed } \\
\text { diagnosis }\end{array}$} & $\begin{array}{l}\text { Low- } \\
\text { functioning } \\
(n=28)\end{array}$ & $\begin{array}{l}-0.25 \\
(1.14)\end{array}$ & $-0.93(0.98)$ & $+0.43(1.0)$ & $-0.14(1.24)$ & $-0.68(1.28)$ \\
\hline & $\begin{array}{c}\text { High- } \\
\text { functioning } \\
(n=29)\end{array}$ & $\begin{array}{l}-0.34 \\
(1.08)\end{array}$ & $-0.59(1.30)$ & $+0.59(0.87)$ & $+0.10(1.11)$ & $-0.52(1.15)$ \\
\hline \multicolumn{2}{|c|}{ Independent t-tests } & $\begin{array}{l}t(55)= \\
-0.322 \\
=.748\end{array}$ & $\begin{array}{c}t(55)=1.128 \\
p=.265\end{array}$ & $\begin{array}{c}t(55)=0.636 \\
p=.528\end{array}$ & $\begin{array}{c}t(55)=0.789 \\
p=.434\end{array}$ & $\begin{array}{c}t(55)=0.50 \\
p=.619\end{array}$ \\
\hline \multicolumn{2}{|c|}{ Total $(n=57)$} & $\begin{array}{l}-0.30 \\
(1.10)\end{array}$ & $-0.75(1.15)$ & $+0.51(0.93)$ & $-0.02(1.17)$ & $-0.60(1.21)$ \\
\hline \multirow{2}{*}{$\begin{array}{l}\text { Within-family } \\
\text { reports }\end{array}$} & $\begin{array}{c}\text { Autistic } \\
\text { sibling }(n= \\
43)\end{array}$ & $\begin{array}{l}-0.40 \\
(1.12)\end{array}$ & $-0.74(1.18)$ & $+0.44(0.91)$ & $-0.09(1.23)$ & $-0.58(1.22)$ \\
\hline & $\begin{array}{c}\text { Neurotypical } \\
\text { sibling }(n= \\
43)\end{array}$ & $\begin{array}{l}-0.44 \\
(0.93)\end{array}$ & $-0.19(0.91)$ & +0.47 & $+0.05(1.0)$ & $-0.26(1.11)$ \\
\hline \multicolumn{2}{|c|}{ Paired t-tests } & $\begin{array}{c}t(42)= \\
0.323 \\
p= \\
.743\end{array}$ & $\begin{array}{c}t(42)=-2.439 \\
p=.019\end{array}$ & $\begin{array}{c}t(42)= \\
-0.147, p= \\
.884\end{array}$ & $\begin{aligned} t(42) & =-0.650 \\
p & =.519\end{aligned}$ & $\begin{array}{c}t(42)=-1.207 \\
p=.234\end{array}$ \\
\hline
\end{tabular}

Note. The 5-point scale ranged from -2 to 2 , so negative numbers indicate a decrease in the relevant function, positive numbers an increase. A paired t-test comparing children with ASD to neurotypical control children was significant regarding adaptation abilities. All other t-tests were not significant. Note that sample sizes are small and differ since comparisons between high- and low-functional autistic children show independent t-tests for all children with autism reported in the survey $(n=57)$, while comparisons between autistic and neurotypical children show paired t-tests for siblings within families $(n=$ 43). 


\section{Brief Summary of the Online Survey Results}

Our parent survey confirmed with the standardized PedsQL ${ }^{\mathrm{TM}}$ dimensions emotional functioning and social functioning that children with autism scored considerably lower than their control children who shared the same family environment and situation. On our change-based measures that focussed on different social and behavioural aspects (i.e., general well-being, coping/adaptation abilities, overall anxiety, emotional reactions, and social behaviours) before and at the peak of the pandemic, the extent of negative change was comparable for children with autism and neurotypical children, except for coping/adaptation abilities. The latter was noted as significantly stronger for children with autism compared with neurotypical children. Note, that our working hypothesis of better outcomes for individuals with autism was not confirmed on any of our measures. On a precautionary note, all our measures showed a wide spread of responses, indicating that some individuals and/or families struggled hugely under pandemic restrictions, while others coped quite well. Along those lines, some positive findings in this survey were that most children responded comparatively well to recommended hygiene behaviour, except that autistic children were hesitant about wearing face masks. Further, and similarly as reported in some papers from our systematic review, families spent more time together and experienced greater emotional closeness within the family.

\section{Single-Case Reports from Early Support and Counselling Center Jena, Germany}

In Jena, Germany, the Early Support and Counselling Center was forced by the local authorities to stop offering physical special needs services in kindergartens, schools, and homes in the affected families. The change was sudden, and many parents of children with autism reported that it elicited considerable stress and anxiety due to the loss of daily routines and insights from a third party. Here we report on two specific narrative experiences as reported to the early support and counselling service point Jena:

J., a 12-year-old boy with atypical autism visiting a special school, normally likes his school; his mother and caregivers report that he often engages in role-playing and enters his own imaginary world when feeling overwhelmed. During German school closures in Spring 2020, he played "school" all day long in his room. Although he did attend classwork, his mother reported that he is otherwise almost impossible to contact in his imaginary world. The situation improved during summer, but after the second school closure in late 2020 , he typically refused to leave his 
own room and refused to do classwork. When he was allowed back to childcare in his school in February 2021, he was jubilant to have his school back.

L., a 14-year-old boy with high-functional autism who usually likes going to high school where he regularly obtains very good to good grades, coped well with the first German lockdown in Spring 2020. Parents and caregivers reported that he developed a good structure, regularly submitted quality classwork from home to his teachers, and he generally enjoyed homeschooling very much. However, after schools re-opened in late Spring 2020, L. did not physically attend classes until the summer break, apparently because of his asthma as a risk condition. In the second German lockdown in November 2020, he coped even less well, found the school internet cloud to be poorly structured, and generally was overwhelmed by the multitude of tasks. L. did not ask his parents for help because he "was used to managing on his own" and did not confess that he had difficulties meeting demands until the teacher informed parents that he had stopped submitting classwork altogether.

On a positive note, the Early Support and Counselling Center Jena, Germany, reports that most adults with autism experienced the lockdown as less problematic and sometimes even as relaxing due to the reduction of face-to-face social contacts. Manyents also reported positive effects on their family life, which they attributed to more time spent on physical activities, such as hiking, play, or music.

\section{Brief Summary of Single-Case Reports}

Like those offered by the Early Support and Counselling Center Jena, Germany, support services were restricted by law. This loss posed an additional challenge to children with autism and their families, as third-party support was unable to intervene when an increase in ASD core symptoms was observed. It was reported that the younger the affected individuals, the more they struggled with the Covid-19-induced changes. Interestingly, family relationships were generally described as positively different, as more leisure time was spent together.

\section{General Discussion}

An efficient response to the challenges of the COVID-19 crisis requires a massive effort from the social and behavioural sciences ${ }^{[69]}$, to reveal more information on potentially devastating effects of the pandemic on vulnerable individuals, like those affected by autism. In the current paper, we provided a systematic review of qualitative and quantitative works on individuals and families 
affected by autism during the global COVID-19 pandemic, considering publications from 2020 to February 1, 2021. Further, we provide results from a parent-survey of school-age children and adolescents with and without a clinical diagnosis of autism from within one family household, conducted from July 16 to September 22, 2020. We then provide examples of autism case-reports from the Early Support and Counselling Center Jena, Germany.

From our systematic review, it became clear that more cumulative research is needed both to quantify pandemic effects on autistic individuals requiring various levels of support, and to further develop, optimize, and evaluate support offers for schooling and telehealth interventions. At the same time, and unsurprisingly, there are still critical gaps in knowledge. To fill these blind spots, we anticipate that researchers' global effort will be needed to integrate data from across the world and different pandemic phases. In the studies we reviewed, we also identified topics that were covered only occasionally (sometimes only in one study). Some will be highlighted here as they cross the borders of social behavioural and medical sciences and are still very rare.

We anticipate and welcome further work towards a holistic approach that considers mental and physical characteristics of autistic individuals. For instance, in an editorial letter, Baghdadli et al ${ }^{[70]}$ pointed out that autistic people with more severe intellectual disabilities may be particularly vulnerable due to their living situation, but also because they can have immune systems with increased levels of inflammatory cytokines, putting them at increased risk for severe forms of COVID-19. Another issue that has been considered in the study by Türkoğlu et $a^{a{ }^{[71]}}$ was sleep problems of children with ASD during the COVID-19 pandemic, their relationship to symptom severity, and perspectives of reducing sleep problems to mitigate negative effects.

Special needs should be considered for people with autism who are hospitalized with COVID-19. Two papers from the same institute in Paris ${ }^{[72,73]}$ report initial experiences and quantitative data from a COVID unit for autistic patients only, created in an interdisciplinary collaboration between child and adolescent psychiatry and specialists for infectious diseases. The authors describe how this improved the response to both specific psychological and medical characteristics of patients with ASD (e.g., due to higher prevalence of gastrointestinal or immunological disorders). Amongst other measures, non-invasive methods when ventilation is needed should be considered more systematically in those approaches ${ }^{[74]}$ in order to reduce anxiety and arousal. In parallel, better routines need to be developed and evaluated to meet the 
need for home-based testing for COVID-19 infections in ASD in a way that considers sensory concerns and compliance of individuals with autism ${ }^{[35]}$.

For our parent-survey of school-age children and adolescents with and without a clinical diagnosis of autism we are acknowledging our analyses' limitations due to the comparatively small number of respondents. At the same time, we believe that they provide some useful and relevant insights for future research. As such, we recommend sampling autistic and non-autistic individuals from the same (family/care) environment where feasible, in order to make conclusions more autism-specific and less dependent on societal and cultural influences. Further, change-based measures comparing effects in more relaxed and more constrained pandemic times (e.g., trough vs. peak of a wave; summer vs. winter; soft vs. hard lockdown measures) also seem important in order to keep societal and cultural influences better controlled. On a more critical note, we point out that third-party reports from parents and primary-caregivers of affected individuals with autism may be biased more than, for instance, reports from support services, teachers, therapists or medical staff. Future policy-makers may want to consider that, while acknowledging that parent or primary-caregiver reports are valuable in their own right. For instance, they can give insights that more objective reports can never provide, by posing a social norm that individuals with autism tend to adhere to, and as such mask their autism characteristics ${ }^{[75]}$.

Finally, we would like to mention a few positive findings. Although the numbers are hard to interpret, it seems that most children responded comparatively well to recommended hygiene behaviour, with the exception that autistic children were hesitant about wearing face masks. When integrated with others' findings reviewed in this paper, and if this will be corroborated by further research, we believe the evidence that children with autism can adhere well to these recommendations when conveyed appropriately is encouraging. Also consistent with other findings ${ }^{\text {[e.g., } 25]}$, the present data indicate two other positive aspects. Specifically, due to either advice or legislation to stay at home, families with children with autism spent more time together, and experienced greater emotional closeness within the family. Without a doubt, this could contribute to resilience in the face of profound challenges and to parents' and childrens' ability to deal with these difficulties - an aspect that is not always reflected in press reports. 


\section{Perspectives}

The present work has made clear that more research, especially in hitherto neglected areas, is needed both to quantify pandemic effects on autistic individuals requiring various levels of support, and to further develop, optimize, and evaluate support offers for schooling and telehealth. Beyond that, it seems appropriate to reflect on challenges and changes the pandemic imposes on our societies in general, and on the impact these changes can have on neurotypical people and people with autism in the longer term.

When considering the psychological and neurobiological effects of social isolation, it is hardly surprising that the degree of isolation many humans experience during the COVID-19 pandemic is a likely threat for mental and bodily health. In a recent feature review in response to the pandemic, Bzdok and Dunbar ${ }^{[76]}$ summarize the important role of social bonds for specific aspects of human health, and illustrate why some forms of digital communication cannot well compensate for real-time face-to-face interaction. When communicating, our brains are tuned to process multiple simultaneous signals from different senses, to use prosody and eye contact to steer a conversation or joint action, and to process dynamic representations of the face, the voice, bodily motion and other activities from a partner ${ }^{[77]}$. Recent research suggests that social interaction is a critical driving factor that shapes brains through the lifetime ${ }^{[78]}$, and that has shaped the human brain during evolution ${ }^{[79]}$. Bzdok and Dunbar ${ }^{[76]}$ consider several effective means to mitigate costs of isolation, such as supporting friendships, mental training towards empathy or perspective-taking of others' mental states, or joint singing. Although joint singing typically happens in choirs and singing groups, the internet has enabled musicians to perform together over distances via imitation and remix. We may be struck by the success of Scots' postman Nathan Evans, who in December 2020 became famous after posting the 19th-century shanty "The Wellerman". This example, and the overwhelmingly positive response of people suffering from social isolation, could point to a therapeutic form of social interaction via digital media that is not (much) compromised by their technological limitations. In this instance, it may help that familiar music is temporally predictable, making it easy to sing or play along, while eye contact is of little or no relevance.

It can be expected that people with autism suffer from social isolation too. Although certain behavioural signs in autism (such as low levels of eye contact) have long been taken as an indicator for their lack of social interest or motivation, this interpretation is likely incorrect. 
Instead, autistic people just express their social motivation in unconventional manners ${ }^{[80,81]}$. Mitchell et al ${ }^{[81]}$ emphasize how being misperceived, against the background of social conventions, creates risks for mental health and well-being of autistic people. The "double empathy problem" describes how autistic individuals find fitting into society difficult not only because they misunderstand others, but also because they are misunderstood by others reflecting a bidirectional failure of empathy ${ }^{[81]}$. In some sense, the COVID-19 pandemic has submitted humankind to a global experiment, in which established social conventions (e.g., handshaking, keeping distance according to one's peripersonal comfort zone, preferring faceto-face communication) have been eroded or are changing dramatically, creating ruptures in social interaction for everyone. While we need to take the associated risks seriously, the current situation of changing social conventions could also provide potential and chances to promote a better and more humane understanding between autistic and neurotypical people in moments of crisis.

Finally, although this article focuses on children, changes relating to social distancing are affecting children and adults, and schools and employment. Regarding prospects for work opportunities in a difficult economy, one study from the UK ${ }^{[82]}$ assessed 78 individuals with mental handicaps, who reported that the most essential flexible working opportunity to help them work efficiently was a safe and quiet place to go when overwhelmed. Data for that study were actually collected in summer 2019 , but the results were discussed in the context of the pandemic. The paper, published in an outlet in business and economy, gives an impressive account of how societies currently waste potential to empower adults with autism, and how this potential could be used for both integration and economic and financial success. As telework often seems to provide an optimal context for good performance, we believe the pandemic could provide a unique window of opportunity in several fields which will ultimately become important not only for children, but also for employers and many adults with autism.

\section{Author Note}

Author contributions: Design and discussion of the online survey: HK, DS, SSD, CD, AEK, SRS. Implementation of the online survey: DS, HK, with input from SSD, CD regarding different language versions. Data analysis and report of the online survey: $\mathrm{HK}, \mathrm{CD}$, all authors. Plan and evaluation of material for the systematic review: AEK, JR, SRS. Systematic review writing: AEK, SRS, all authors. Practician and caregivers viewpoints: GK, all authors. Supplemental Material: $\mathrm{CD}$, all authors. We thank Franziska Kramer for her help with data processing (online survey). 


\section{References}

[1] Schneider, D., Glaser, M., \& Senju, A. (2017). Autism Spectrum Disorder. In: V. Zeigler-Hill, T.K. Shackelford (Eds.), Encyclopedia of Personality and Individual Differences.Springer International Publishing AG. pp. 329 - 333.

[2] Narzisi A. (2020). Handle the Autism Spectrum Condition during Coronavirus (COVID-19) Stay at Home Period: Ten Tips for Helping Parents and Caregivers of Young Children. Brain Sciences, 10(4):207. https://doi.org/10.3390/brainsci10040207

[3] Jefsen, O. H., Rohde, C., Nørremark, B., \& Østergaard, S. D. (2020). Editorial Perspective: COVID19 pandemic-related psychopathology in children and adolescents with mental illness. Journal of Child Psychology and Psychiatry, and Allied Disciplines, 10.1111/jcpp.13292. Advance online publication. https://doi.org/10.1111/jcpp.13292

[4] Wang, C. (2020). The impact of COVID-19 on autism research: Reflections from China. Autism Research, 13(7), 1028-1028. https://doi.org/10.1002/aur.2344

[5] Espinosa, D. F., Metko, A., Raimondi, M., Impenna, M., \& Scognamiglio, E. (2020). A model of support for families of children with autism living in the COVID-19 lockdown: Lessons from Italy. Behavior Analysis in Practice, 13, 550-558. https://doi.org/10.1007/s40617-020-00438-7

[6] Nonweiler, J., Rattray, F., Baulcomb, J., Happé, F., \& Absoud, M. (2020). Prevalence and associated factors of emotional and behavioural difficulties during COVID-19 pandemic in children with neurodevelopmental disorders. Children, 7(9), 128.

https://doi.org/10.3390/children7090128

[7] Jeste, S., Hyde, C., Distefano, C., Halladay, A., Ray, S., Porath, M., ... \& Thurm, A. (2020). Changes in access to educational and healthcare services for individuals with intellectual and developmental disabilities during COVID-19 restrictions. Journal of Intellectual Disability Research, 64(11), 825-833. https://doi.org/10.1111/jir.12776

[8] Beaumont, R., Walker, H., Weiss, J., \& Sofronoff, K. Randomized Controlled Trial of a Video Gaming-Based Social Skills Program for Children on the Autism Spectrum. Journal of Autism and Developmental Disorders, 1-14. https://doi.org/10.1007/s10803-020-04801-z

[9] Alhuzimi, T. (2021). Stress and emotional wellbeing of parents due to change in routine for children with Autism Spectrum Disorder (ASD) at home during COVID-19 pandemic in Saudi Arabia. Research in Developmental Disabilities, 108, 103822. https://doi.org/10.1016/j.ridd.2020.103822

[10] Samadi, S. A., Bakhshalizadeh-Moradi, S., Khandani, F., Foladgar, M., Poursaid-Mohammad, M., \& McConkey, R. (2020). Using Hybrid Telepractice for Supporting Parents of Children with ASD during the COVID-19 Lockdown: A Feasibility Study in Iran. Brain Sciences, 10(11), 892. https://doi.org/10.3390/brainsci10110892

[11] Kawabe, K., Hosokawa, R., Nakachi, K., Yoshino, A., Horiuchi, F., \& Ueno, S. (2020a, Dec). Excessive and Problematic Internet Use During the Coronavirus Disease 2019 School Closure: Comparison Between Japanese Youth With and Without Autism Spectrum Disorder. Frontiers in Public Health, 8, Article 609347. https://doi.org/10.3389/fpubh.2020.609347

[12] Cahapay, M. B. (2020). How Filipino parents home educate their children with autism during COVID-19 period. International Journal of Developmental Disabilities, 1-4. https://doi.org/10.1080/20473869.2020.1780554 
[13] Majoko, T., \& Dudu, A. (2020). Parents' strategies for home educating their children with Autism Spectrum Disorder during the COVID-19 period in Zimbabwe. International Journal of Developmental Disabilities, 1-5. https://doi.org/10.1080/20473869.2020.1803025

[14] Echavarria-Ramirez, L., Diaz-Reyes, D. V., \& Narzisi, A. (2020, Jan-Apr). Autism Spectrum Disorder: Guidelines for management during the period of Social Isolation by Coronavirus (COVID-19). Cuadernos De Neuropsicologia-Panamerican Journal of Neuropsychology, 14(1), 35. https://doi.org/10.7714/cnps/14.1.205

[15] American Psychiatric Association. (2013). Diagnostic and statistical manual of mental disorders (DSM-5®). American Psychiatric Pub.

[16] Bellomo, T. R., Prasad, S., Munzer, T., \& Laventhal, N. (2020). The impact of the COVID-19 pandemic on children with autism spectrum disorders. Journal of Pediatric Rehabilitation Medicine, (Preprint), 1-6. https://doi.org/10.3233/PRM-200740

[17] Courtenay, K., \& Perera, B. (2020). COVID-19 and people with intellectual disability: impacts of a pandemic. Irish Journal of Psychological Medicine, 37(3), 231-236.

https://doi.org/10.1017/ipm.2020.45

[18] Newbutt, N., Schmidt, M. M., Riva, G., \& Schmidt, C. (2020). The possibility and importance of immersive technologies during COVID-19 for autistic people. Journal of Enabling Technologies. https://doi.org/10.1108/jet-07-2020-0028

[19] Colizzi, M., Sironi, E., Antonini, F., Ciceri, M. L., Bovo, C., \& Zoccante, L. (2020). Psychosocial and behavioral impact of COVID-19 in autism spectrum disorder: an online parent survey. Brain Sciences, 10(6), 341.https://doi.org/10.3390/brainsci10060341

[20] Ren, J., Li, X., Chen, S., Chen, S., \& Nie, Y. (2020). The Influence of Factors Such as Parenting Stress and Social Support on the State Anxiety in Parents of Special Needs Children During the COVID-19 Epidemic. Frontiers in Psychology, 11. https://doi.org/10.3389/fpsyg.2020.565393

[21] Chen, S. Q., Chen, S. D., Li, X. K., \& Ren, J. (2020). Mental health of parents of special needs children in china during the covid-19 pandemic. International Journal of Environmental Research and Public Health, 17(24), 9519. https://doi.org/10.3390/ijerph17249519

[22] Manning, J., Billian, J., Matson, J., Allen, C., \& Soares, N. (2020). Perceptions of Families of Individuals with Autism Spectrum Disorder during the COVID-19 Crisis. Journal of Autism and Developmental Disorders, 1-9. https://doi.org/10.1007/s10803-020-04760-5

[23] Amorim, R., Catarino, S., Miragaia, P., Ferreras, C., Viana, V., \& Guardiano, M. (2020). The impact of COVID-19 on children with autism spectrum disorder. https://doi.org/10.33588/rn.7108.2020381

[24] Redquest, B. K., Tint, A., Ries, H., \& Lunsky, Y. (2021). Exploring the experiences of siblings of adults with intellectual/developmental disabilities during the COVID-19 pandemic. Journal of Intellectual Disability Research, 65(1), 1-10.https://doi.org/10.1111/jir.12793

[25] Alyoubi, R. A., \& Ebtisam, A. A. (2020). Experiences of Parenting Child with ASD during COVID-19 Pandemic: A Cross-Sectional Study. Medical Science, 24(106), 3972-3980. ISSN: 0767-0974

[26] Neece, C., Mclntyre, L. L., \& Fenning, R. (2020). Examining the impact of COVID-19 in ethnically diverse families with young children with intellectual and developmental disabilities. Journal of Intellectual Disability Research, 64(10), 739-749.https://doi.org/10.1111/jir.12769

[27] Asbury, K., Fox, L., Deniz, E., Code, A., \& Toseeb, U. (2020). How is COVID-19 affecting the mental health of children with special educational needs and disabilities and their 
families?. Journal of Autism and Developmental Disorders, 1-9. https://doi.org/10.1007/s10803020-04577-2

[28] Mutluer, T., Doenyas, C., \& Genc, H. A. (2020). Behavioral Implications of the Covid-19 Process for Autism Spectrum Disorder, and Individuals' Comprehension of and Reactions to the Pandemic Conditions. Frontiers in Psychiatry, 11. https://doi.org/10.3389/fpsyt.2020.561882

[29] Parenteau, C. I., Bent, S., Hendren, R. L., Hossain, B., Y., Widjaja, F., \& Breard, M. (2020). 51.1 A qualitative analysis: the experience of parents of children with autism spectrum disorder during the covid-19 pandemic. Journal of the American Academy of Child and Adolescent Psychiatry, 59(10), S251.https://doi.org/10.1016/j.jaac.2020.08.411

[30] White, L. C., Law, J. K., Daniels, A. M., Toroney, J., Vernoia, B., Xiao, S., ... \& Chung, W. K. Brief Report: Impact of COVID-19 on Individuals with ASD and Their Caregivers: A Perspective from the SPARK Cohort. Journal of Autism and Developmental Disorders, 1-8.

https://doi.org/10.1007/s10803-020-04816-6

[31] Kawabe, K., Hosokawa, R., Nakachi, K., Yoshino, A., Horiuchi, F., \& Ueno, S. (2020b, Sep). Making a brochure about coronavirus disease (COVID-19) for children with autism spectrum disorder and their family members. Psychiatry and Clinical Neurosciences, 74(9), 498-499. https://doi.org/10.1111/pcn.13090

[32] Stenhoff, D. M., Pennington, R. C., \& Tapp, M. C. (2020). Distance education support for students with autism spectrum disorder and complex needs during covid-19 and school closures. Rural Special Education Quarterly, 39(4), 211-219. https://doi.org/10.1177/8756870520959658

[33] Yarımkaya, E., \& Esentürk, O. K. (2020). Promoting physical activity for children with autism spectrum disorders during Coronavirus outbreak: benefits, strategies, and examples. International Journal of Developmental Disabilities, Early Access, 1-6. https://doi.org/10.1080/20473869.2020.1756115

[34] Brondino, N., Damiani, S., \& Politi, P. (2020). Effective strategies for managing COVID-19 emergency restrictions for adults with severe ASD in a daycare center in Italy. Brain Sciences, 10(7), 436. https://doi.org/10.3390/brainsci10070436

[35] Eshraghi, A. A., Li, C., Alessandri, M., Messinger, D. S., Eshraghi, R. S., Mittal, R., \& Armstrong, F. D. (2020). COVID-19: overcoming the challenges faced by individuals with autism and their families. The Lancet Psychiatry, 7(6), 481-483. https://doi.org/10.1016/S2215-0366(20)30197-8

[36] Baron-Cohen, S., Richler, J., Bisarya, D., Gurunathan, N., \& Wheelwright, S. (2003). The systemizing quotient: an investigation of adults with Asperger syndrome or high-functioning autism, and normal sex differences. Philosophical Transactions of the Royal Society of London Series B-Biological Sciences, 358(1430), 361-374. https://doi.org/10.1098/rstb.2002.1206

[37] Pennisi, P., Tonacci, A., Tartarisco, G., Billeci, L., Ruta, L., Gangemi, S., \& Pioggia, G. (2016). Autism and social robotics: A systematic review. Autism Research, 9(2), 165183. https://doi.org/10.1002/aur.1527

[38] Kowallik, A. E., \& Schweinberger, S. R. (2019). Sensor-Based Technology for Social Information Processing in Autism: A Review. Sensors, 19(21), 4787. https://doi.org/10.3390/s19214787

[39] Reicher, D. (2020). Debate: Remote learning during COVID-19 for children with high functioning autism spectrum disorder. Child and Adolescent Mental Health, 25(4), 263-264.

https://doi.org/10.1111/camh.12425

[40] Sivaraman, M., Virues-Ortega, J., \& Roeyers, H. (2020). Telehealth mask wearing training for children with autism during the COVID-19 pandemic. Journal of Applied Behavior Analysis. https://doi.org/10.1002/jaba.802 
[41] Crockett, J. L., Becraft, J. L., Phillips, S. T., Wakeman, M., \& Cataldo, M. F. (2020). Rapid Conversion from Clinic to Telehealth Behavioral Services During the COVID-19 Pandemic. Behavior Analysis in Practice, 13(4), 725-735. https://doi.org/10.1007/s40617-020$\underline{00499-8}$

[42] Tohidast, S. A., Mansuri, B., Bagheri, R., \& Azimi, H. (2020). Provision of speech-language pathology services for the treatment of speech and language disorders in children during the COVID-19 pandemic: Problems, concerns, and solutions. International Journal of Pediatric Otorhinolaryngology, 138, 110262. https://doi.org/10.1016/j.ijporl.2020.110262

[43] Kalvin, C. B., Jordan, R. P., Rowley, S. N., Weis, A., Wood, K. S., Wood, J. J., ... \& Sukhodolsky, D. G. (2021). Conducting CBT for Anxiety in Children with Autism Spectrum Disorder During COVID-19 Pandemic. Journal of Autism and Developmental Disorders, Advance Online, 1-9. https://doi.org/10.1007/s10803-020-04845-1

[44] Conti, E., Chericoni, N., Costanzo, V., Lasala, R., Mancini, A., Prosperi, M., ... \& Apicella, F. (2020). Moving Toward Telehealth Surveillance Services for Toddlers at Risk for Autism During the COVID-19 Pandemic. Frontiers in Psychiatry, 11. https://doi.org/10.3389/fpsyt.2020.565999

[45] Wagner, L., Corona, L. L., Weitlauf, A. S., Marsh, K. L., Berman, A. F., Broderick, N. A., ... \& Warren, Z. (2020). Use of the TELE-ASD-PEDS for autism evaluations in response to COVID19: Preliminary outcomes and clinician acceptability. Journal of Autism and Developmental Disorders, 1-10. https://doi.org/10.1007/s10803-020-04767-y

[46] Narzisi, A. (2020). Phase 2 and Later of COVID-19 Lockdown: Is it Possible to Perform Remote Diagnosis and Intervention for Autism Spectrum Disorder? An Online-Mediated Approach. Journal of Clinical Medicine, 9(6), Article 1850. https://doi.org/10.3390/jcm9061850

[47] Summers, J., Baribeau, D., Mockford, M., Goldhopf, L., Ambrozewicz, P., Szatmari, P., \& Vorstman, J. (2021). Supporting Children With Neurodevelopmental Disorders During the COVID-19 Pandemic. Journal of the American Academy of Child and Adolescent Psychiatry, 60(1), 2-6. https://doi.org/10.1016/j.jaac.2020.09.011

[48] Eapen, V., Hiscock, H., \& Williams, K. (2021). Adaptive innovations to provide services to children with developmental disabilities during the COVID-19 pandemic. Journal of Paediatrics and Child Health, 57(1), 9-11. https://doi.org/10.1111/jpc.15224

[49] Ameis, S. H., Lai, M. C., Mulsant, B. H., \& Szatmari, P. (2020). Coping, fostering resilience, and driving care innovation for autistic people and their families during the COVID-19 pandemic and beyond. Molecular Autism, 11(1), 1-9. https://doi.org/10.1186/s13229-020-00365-y

[50] Nadler, C., Godwin, D. L., Dempsey, J., \& Nyp, S. S. (2021). Autism and Access to Care During the COVID-19 Crisis. Journal of Developmental \& Behavioral Pediatrics, 42(1), 73-75. https://doi.org/10.1097/dbp.0000000000000894

[51] Loman, M., Vogt, E., Miller, L., Landsman, R., Duong, P., Kasten, J., ... \& Heffelfinger, A. (2020). "How to" operate a pediatric neuropsychology practice during the COVID-19 pandemic: Real tips from one practice's experience. Child Neuropsychology, 1-29.

https://doi.org/10.1080/09297049.2020.1830962

[52] Joseph, B., Kearney, K. B., Brady, M. P., Downey, A., \& Torres, A. (2021). Teaching Small Talk: Increasing On-Topic Conversational Exchanges in College Students with Intellectual and Developmental Disabilities Using Remote Audio Coaching. Behavior Modification, 45(2), 251271. https://doi.org/10.1177/0145445520975174 
[53] Drozdowicz, L., Gordon, E., Shapiro, D., Jacobson, S., Zalpuri, I., Stewart, C., ... \& Martin, A. (2020). Sexual health in child and adolescent psychiatry: multi-site implementation through synchronized videoconferencing of an educational resource using standardized patients. Frontiers in Psychiatry, 11, 1160. https://doi.org/10.3389/fpsyt.2020.593101

[54] Cox, D. J., Plavnick, J. B., \& Brodhead, M. T. (2020). A proposed process for risk mitigation during the COVID-19 pandemic. Behavior Analysis in Practice, 13(2), 299-305. https://doi.org/10.1007/s40617-020-00430-1

[55] Schieltz, K. M., \& Wacker, D. P. (2020). Functional assessment and function-based treatment delivered via telehealth: A brief summary. Journal of Applied Behavior Analysis, 53(3), 12421258. https://doi.org/10.1002/jaba.742

[56] Rodriguez, K. A. (2020). Maintaining treatment integrity in the face of crisis: A treatment selection model for transitioning direct ABA services to telehealth. Behavior Analysis in Practice, 13(2), 291-298. https://doi.org/10.1007/s40617-020-00429-8

[57] Colombo, R. A., Wallace, M., \& Taylor, R. (2020). An essential service decision model for ABA providers during crisis. Behavior Analysis in Practice, 13, 306-311. https://doi.org/10.1007/s40617-020-00432-z

[58] Kornack, J., Williams, A.L., Johnson, KIA., \& Mendes, E.M. (2020). Reopening the Doors to Center-Based ABA Services: Clinical and Safety Protocols during COVID-19. Behavior Analysis in Practice, 13, 543-549. https://doi.org/10.1007/s40617-020-00462-7

[59] Yi, Z., \& Dixon, M. R. (2020). Developing and enhancing adherence to a telehealth ABA parent training curriculum for caregivers of children with autism. Behavior Analysis in Practice, Advance Online, 1-17. https://doi.org/10.1007/s40617-020-00464-5

[60] Nicolson, A. C., Lazo-Pearson, J. F., \& Shandy, J. (2020). ABA Finding Its Heart During a Pandemic: An Exploration in Social Validity. Behavior Analysis in Practice, 13, 757-766. https://doi.org/10.1007/s40617-020-00517-9

[61] Pollard, J. S., LeBlanc, L. A., Griffin, C. A., \& Baker, J. M. (2021). The effects of transition to technician-delivered telehealth ABA treatment during the COVID-19 crisis: A preliminary analysis. Journal of Applied Behavior Analysis, 54(1), 87-102. https://doi.org/10.1002/jaba.803

[62] Szabo, T. G., Richling, S., Embry, D. D., Biglan, A., \& Wilson, K. G. (2020). From helpless to hero: Promoting values-based behavior and positive family interaction in the midst of COVID19. Behavior Analysis in Practice, 13(3), 568-576. https://doi.org/10.1007/s40617-020-00431-0

[63] Saline, S. (2021). Thriving in the New Normal: How COVID-19 has Affected Alternative Learners and Their Families and Implementing Effective, Creative Therapeutic Interventions. Smith College Studies in Social Work, Advance Online, 1-28.

https://doi.org/10.1080/00377317.2020.1867699

[64] Tarbox, C. M., Silverman, E. A., Chastain, A. N., Little, A., Bermudez, T. L., \& Tarbox, J. (2020). Taking ACTion: 18 simple strategies for supporting children with autism during the COVID-19 pandemic. Behavior Analysis in Practice, Advance Online, 1-29. https://doi.org/10.1007/s40617-020-00448-5

[65] Faul, F., Erdfelder, E., Buchner, A., \& Lang, A.-G. (2009). Statistical power analyses using G*Power 3.1: Tests for correlation and regression analyses. Behavior Research Methods, 41, 1149-1160. https://doi.org/10.3758/BRM.41.4.1149

[66] Leiner, D. J. (2019). SoSci Survey (Version 3.2.21) [Computer software]. Available at https://www.soscisurvey.de 
[67] Allison, C., Auyeung, B., \& Baron-Cohen, S. (2012). Toward brief "red flags" for autism screening: the short autism spectrum quotient and the short quantitative checklist in 1,000 cases and 3,000 controls. Journal of the American Academy of Child \& Adolescent Psychiatry, 51(2), 202-212. https://doi.org/10.1016/j.jaac.2011.11.003

[68] Varni, J. W., Seid, M., \& Kurtin, P. S. (2001). PedsQL ${ }^{\mathrm{TM}}$ 4.0: Reliability and validity of the Pediatric Quality of Life Inventory version 4.0 generic core scales in healthy and patient populations. Medical Care, 39(8). 800-12 https://doi.org/10.1097/00005650-200108000-00006

[69] Van Bavel, J. J., Baicker, K., Boggio, P. S., Capraro, V., Cichocka, A., Cikara, M., ... \& Willer, R. (2020). Using social and behavioural science to support COVID-19 pandemic response. Nature Human Behaviour, 4(5), 460-471. https://doi.org/10.1038/s41562-020-0884-z

[70] Baghdadli, A., Picot, M. C., Miot, S., \& Munir, K. (2020). A Call to Action to Implement Effective COVID-19 Prevention and Screening of Individuals with Severe Intellectual Developmental and Autism Spectrum Disorders. Journal of Autism and Developmental Disorders, Advance Online, 1-3. https://doi.org/10.1007/s10803-020-04719-6

[71] Türkoglu, S., Ucar, H. N., Cetin, F. H., Guler, H. A., \& Tezcan, M. E. (2020). The relationship between chronotype, sleep, and autism symptom severity in children with ASD in COVID-19 home confinement period. Chronobiology International, 37(8), 12071213. https://doi.org/10.1080/07420528.2020.1792485

[72] Cohen, D. (2020). Appréhender le COVID-19 au fil de l'eau en tant que psychiatre d'enfant et d'adolescent. L'encephale, 46(3), S99-S106. https://doi.org/10.1016/j.encep.2020.05.005

[73] Nollace, L., Cravero, C., Abbou, A., Mazda-Walter, B., Bleibtreu, A., Pereirra, N., ... \& Giannitelli, M. (2020). Autism and COVID-19: A Case Series in a Neurodevelopmental Unit. Journal of Clinical Medicine, 9(9), 2937. https://doi.org/10.3390/jcm9092937

[74] Schmidt, B., Schneider, J., Deffner, T., \& Rosendahl, J. (2021). Hypnotic suggestions of safety improve well-being in non-invasively ventilated patients in the intensive care unit. Intensive care medicine, 1-2. Advance online publication. https://doi.org/10.1007/s00134-021-06364-8

[75] Collette Sosnowy, Chloe Silverman, Paul Shattuck, and Tamara Garfield.Autism in Adulthood.Mar 2019.44-51.http://doi.org/10.1089/aut.2018.0009

[76] Bzdok, D., \& Dunbar, R. I. (2020). The neurobiology of social distance. Trends in Cognitive Sciences. https://doi.org/10.1016/j.tics.2020.05.016

[77] Young, A. W., Frühholz, S., \& Schweinberger, S. R. (2020). Face and voice perception: understanding commonalities and differences. Trends in Cognitive Sciences, 24(5), 398-410. https://doi.org/10.1016/j.tics.2020.02.001

[78] Hari, R., Henriksson, L., Malinen, S., \& Parkkonen, L. (2015). Centrality of social interaction in human brain function. Neuron, 88(1), 181-193. https://doi.org/10.1016/j.neuron.2015.09.022

[79] Dunbar, R. I., \& Shultz, S. (2007). Evolution in the social brain. science, 317(5843), 1344-1347. https://doi.org/10.1126/science.1145463

[80] Jaswal, V. K., \& Akhtar, N. (2019). Being versus appearing socially uninterested: Challenging assumptions about social motivation in autism. Behavioral and Brain Sciences, 42(e82), 1-73. https://doi.org/10.1017/s0140525x18001826

[81] Mitchell, P., Sheppard, E., \& Cassidy, S. (2021). Autism and the double empathy problem: Implications for development and mental health. British Journal of Developmental Psychology. https://doi.org/10.1111/bjdp.12350

[82] Warmate, Z., Eldaly, M. K., \& Elamer, A. A. (2020). Offering flexible working opportunities to people with mental disabilities: The missing link between sustainable development goals and financial implications. Business Strategy and the Environment. https://doi.org/10.1002/bse.2694

[83] Amaral, D. G., \& de Vries, P. J. (2020). COVID-19 and Autism Research: Perspectives from Around the Globe. Autism Research, 13(6), 844-869. https://doi.org/10.1002/aur.2329 


\section{Supplementary Material 1 \\ Detailed Description of the Questionnaire}

This document contains supplemental material of the manuscript:

Kreysa, H., Schneider, D., Kowallik, A.E., Dastgheib, S.S., Doğdu, C., Kühn, G., Rutloff, J., \& Schweinberger S.R. (2021). Psychosocial and Behavioral Effects of the Covid-19 Pandemic on Children with Autism and their Families: A Systematic Review and Initial Data from a Multinational Online Survey [Manuscript submitted for publication].

Online-survey was generated via SoSci Survey (Leiner., 2016) in English and translated into Turkish, German, and Persian (Farsi) by native speakers. Separate links were distributed for each language. Full version of the online questionnaire in English is attached in the Supplementary Material 2 section.

\section{1) Greetings (Screen 1)}

The questionnaire starts with greetings and a brief explanation about the aim of the study (e.g "... how the current pandemic has affected the daily life and wellbeing of families with children with autism in different countries.").

\section{2) Information for Participants (Screen 2)}

Detailed information about the study was presented with a download link.

\section{3) Declaration of Consent (Screen 3)}

Participants were able to declare their consent by clicking the "next" button after they were informed in detail. This declaration included the conditions of voluntary participation and their right to end participation any time they would like. Participants were also informed that the personal data are collected in course of this scientific study under required ethical standards.

\section{4) Code for Anonymity (Screen 4)}

Participants created an anonymous code by using specific combinations of letters and digits of the participants personal information (undisclosed here).

\section{5) Explanation for the Labels: Child A and Child B (Screen 5)}

The labels of Child A (child with Autism) and Child B (one other child without a diagnosis who lives ideally in the same household) were explained with a paragraph: 
" ...we will refer to this child with Autism as Child A. We will also ask you to fill out some questions about one other child (Child B) who ideally lives in the same household. If you do not have another child in your household please report about another child with whom you are in close contact. We will refer to this child as Child B. Child B should not have a clinical diagnosis on the Autism Spectrum. "

\section{6) Socio-demographic Information (Screen 6 / 7)}

Participants were asked about the current information about themselves, their children, where they live, and how the pandemic has affected them. After the question of how many people mostly live in the household, participants filled out this part separately for themselves, Child A, Child B, another sibling, other parent, and another household member. Except for the age, the questions were in multiplechoice format with an - "other"- open answer option particularly for the profession:

- Age (in full years).

- Gender (female, male, other, prefer not to say).

- Profession (pupil/in school, training/apprenticeship, university student, employee- Full time, employee - Part-time, self-employed, unemployed/seeking employment, other).

- Diagnosis ("Is a clinical diagnosis on the Autism Spectrum known for this person?"; Yes/Suspected/No).

\section{7) Diagnosis (Screen 8)}

The severity and comorbidity were asked for Child A:

- "For Child A, please indicate the severity of impairment due to their Autism Spectrum Condition"; requires little or no support / requires support/ requires substantial support / requires substantial support)

- "Is Child A, impaired in any other way?"; yes (open option for further information)/ no, prefer not to say)

\section{8) Autism Quotient - Short (Screen 9)}

Participants filled the 4-point Likert child (parent report) version of the AQ-10 for Child $A$ and Child $B$ separately. Note that only the English version is validated (Allison et al., 2012). For the German, Turkish and Persian (Farsi) languages, the items were taken from the long versions of the AQ-Child. 


\section{9) Socio-Demographic Information - Micro (Screen 10)}

Further information about the accommodation was asked with multiple choice questions with "other" open answer options.

- What kind of accommodation do you live in? Flat/house/other

- Do any household members live somewhere else some of the time? no/yes, please specify

- Does your accommodation have direct access to the outside? Balcony/garden/yard/other, please specify

- How many bedrooms are there in your accommodation?

- Is there a private room for each child in the household? yes/no/unclear

\section{0) Socio-Demographic Information - Macro (Screen 11)}

Participants were asked to report the population size of their community under 6 categories from "less than one hundred" to "more than one million". They reported the country they are currently living in and whether this country is the one that they were born.

\section{1) Corona-Pandemic Restrictions (Screen 12)}

First, they reported whether the pandemic leads to administrative restrictions of school closure and/or complete lockdown at any time. Then, they were asked whether these restrictions are currently still in place with 4-option multiple-choice (yes/no/partially/l don't know) including limits on groups of people, limits on time and activities outside the house, wearing protective clothing/face masks in public, travel restrictions, limits on sports and cultural activities, restrictions for religious events, restricted (non-corona) health-care and therapy options, mandatory quarantine, other (e.g., requirement/encouragement to carry tracking devices, documentation of purpose of visit or health status, ...).

Finally, they reported their personal prediction about the time when the pandemic will be over (1 month / 3 months / 6 months / 1 year / several years / never).

12) Report of the Activities and Time Budgeting for Child A and Child B ( Screen 13/14) 
Participants reported how much time Child A (i.e., the autistic person they are reporting about) spent/spends time on specific activities in a typical 24-hour day for three different time periods namely: "before corona restrictions", "at the peak of the crisis" and "currently". They were instructed to give proportions of the hour (e.g., 30 $\min =0.5$ ) for the following activities:

1. Use of digital devices (smartphone, tablet, laptop) for social communication (e.g. chatting with friends and family).

2. Use of digital devices (smartphone, tablet, laptop) for entertainment (e.g., games, films, surfing the Web).

3. Use of digital devices (smartphone, tablet, laptop) for education (e.g., homeschooling).

4. Use of digital devices (smartphone, tablet, laptop) for -therapy, consultation, and coaching.

5. Special interests and hobbies

6. Inside the house

7. In the garden or on the balcony

8. Outside (but not in your own garden or on your own balcony)

9. Sleeping or in bed.

After that, participants were asked to answer the same questions for Child B (i.e., the other child/adolescent they are reporting about).

\section{3) Health and Well-Being of Children/Adolescents (Screen 15/16)}

In this part, participants rated the following aspects for Child $A$ and Child $B$ separately at present moment in time, compared to the time before the current pandemic (much decreased/slightly decreased/ similar/ slightly increased/ much increased):

- General well-being

- Adaptation abilities

- Overall anxiety levels

- Emotional reactions

- Social behavior

\section{4) Responding to the Pandemic Hygiene Routines (Screen 17)}

Participants indicated separately how Child A and Child B responds to the following pandemic hygiene routines (not applicable/ negative/ neutral/ positive):

- Maintaining physical distance from other people $(1,5 \mathrm{~m})$

- Regular hand- washing

- Use of disinfectant 
- Wearing a face mask

15) PedsQL - Pediatric Quality of Life Inventory (Screen 18-23)

Participants filled out the Version 4.0 - Parent Proxy Report for Children (ages 8-12) of Pediatric Quality of Life Inventory 8 separately Child A and Child B. (PedsQL, Mapi Research Trust; Varni et al., 2001). The questionnaire consists of a total amount of 23 Items on the four distinct dimensions (physical functioning, emotional functioning, social functioning, school functioning).

\section{6) Effects on Entire Family (Screen 24)}

Participants rated the following aspects for their family at the present moment in time, compared to the current pandemic (much decreased/ slightly decreased/ similar/ slightly increased/ much increased):

- Overall stress levels

- Regular daily structure

- Conflict

- Time spent together

- Emotional closeness

\section{7) Support and Challenges (Screen 25/26)}

In this part, participants indicated whether they receive any form of support through the following people or institutions:

- Close family

- Extended family and friends

- Neighbors

- Institutions

- Health service

- Government

After that, there were open-answer parts to ask which (if any) forms of support they find particularly useful and why. Then two additional questions in open-answer format were:

- (How) did the current pandemic affect your child's ASD-specific educational and therapy/ rehabilitation activities?

-Did you experience any other specific challenges during the current pandemic? 
Finally, with an open-box, they were asked to give additional information about any other aspects of the pandemic that were important to them.

\section{References (Supplementary Material 1)}

Allison, C., Auyeung, B., \& Baron-Cohen, S. (2012). Toward brief "red flags" for autism screening: the short autism spectrum quotient and the short quantitative checklist in 1,000 cases and 3,000 controls. Journal of the American Academy of Child \& Adolescent Psychiatry, 51(2), 202-212. https://doi.org/10.1016/j.jaac.2011.11.003

Leiner, D. J. (2019). SoSci Survey (Version 3.2.21) [Computer software]. Available at https://www.soscisurvey.de

Varni, J. W., Seid, M., \& Kurtin, P. S. (2001). PedsQL TM 4.0: Reliability and validity of the Pediatric Quality of Life Inventory version 4.0 generic core scales in healthy and patient populations. Med Care. 2001 Aug;39(8):800-12 https://doi.org/10.1097/00005650-200108000$\underline{00006}$ 


\section{Supplementary Material 2}

Online Questionnaire (English)

This document contains supplemental material of the manuscript:

Kreysa, H., Schneider, D., Kowallik, A.E., Dastgheib, S.S., Doğdu, C., Kühn, G., Rutloff, J., \& Schweinberger S.R. (2021). Psychosocial and Behavioral Effects of the Covid-19 Pandemic on Children with Autism and their Families: A Systematic Review and Initial Data from a Multinational Online Survey [Manuscript submitted for publication]. 
Thank you very much for participating in our survey. The information you provide will help to provide insights into how the current pandemic has affected the daily life and well-being of families with children with autism in different countries.

Please note that you must first read through some ethical guidelines before the actual questionnaire begins.

Also note that there is no "Back" button. Therefore, please read each page carefully before proceeding to the next page and do not use the "Back" function in your Internet browser. Thank you very much.

Information for Participants

Study: "Effects of the coronavirus pandemic on families and individuals with autism spectrum disorders"

By clicking "Next" you confirm that you have read the detailed information about the study that can be downloaded here.

VERY IMPORTANT: For most browser-settings the following applies when clicking on the download link: right click>open in the new tab. Otherwise you will not be able to continue with the questionnaire. 


\section{Declaration of consent}

I was informed in writing about the nature, significance, scope and risks of the scientific study and had the opportunity to clarify my questions about it with the study managers. I was presented with the "Information for Participants" of the study and provided with a download link for this information.

I agree to participate in the study. My participation is voluntary.

I have the right to end my_participation at any time without giving reasons and without any negative consequences for the future.

I accept that the personal data collected in the course of this scientific study:

- will at no time be linked to my real name, place of residence or e-mail address,

- be used exclusively for scientific research,

- will initially only be accessible to the scientists involved in this study (Prof. Dr. Stefan Schweinberger, Dr. Dana Schneider, Dr. Helene Kreysa, Samaneh Dastgheib, Andrea Kowallik and Cem Dogdu) and other members of the research group "Social Potential in Autism" at the Friedrich Schiller University of Jena. For possible continuation or replication work, the data can be made available to other researchers in completely anonymous form,

- will be stored, processed and analysed on electronic data carriers and the results obtained will be published in anonymous form.

By clicking "Next", you confirm your consent.

Please create an anonymous code.

The code consists of the first two letters of your mother's first name, the day you were born, and the last two letters of your own first name.

\section{Example:}

Mother $=$ Monica

Your birthday $=$ October 21st

Your first name $=$ John

Code: MO21HN

Please write your personal code in the blank text field. 
By beginning the questionnaire, you confirm that you are the care-giver for a sch GR05 age child with a clinical diagnosis on the Autism Spectrum, living in the same household.

Important: In the following questionnaire, we will refer to this child with Autism as Child A. We will also ask you to fill out some questions about one other child (Child B) who ideally lives in the same household. If you do not have another child in your household please report about another child with whom you are in close contact. We will refer to this child as Child B. Child B should not have a clinical diagnosis on the Autism Spectrum.

Please note that not all questions in this survey may cover all aspects that were important to you. Therefore, you will find a box for open comments at the end.

In this section, we ask you to provide us with some current information about yourself, your children, where you live, and how the pandemic has affected you.
1
2
3
$\bigcirc 4$
$\bigcirc 5$
$\bigcirc 6$
$\bigcirc 7$
$\bigcirc 8$
$\bigcirc 9$
10
more than 10 
For each household member (beginning with yourself) please provide some basic information.

I am giving detailed information about...

Myself

Child A- with Autism

Child B- without Autism

Other sibling

Other parent

Other household member

Age in full years

Gender

The person is...

female

male

other

prefer not to say

What is the profession of this person?

$\square$ Pupil/in school

$\square$ Training/apprenticeship

$\square$ University student

$\square$ Employee- Full time

$\square$ Employee- Part time

$\square$ Civil servant

$\square$ Self-employed

$\square$ Unemployed/seeking employment Other 
Is a clinical diagnosis on the Autism Spectrum known for this person?
Yes
Suspected
No

\section{I am giving detailed information about...}

Myself

Child A- with Autism

Child B- without Autism

Other sibling

Other parent

Other household member

Age in full years

The person is...

female

male

other

prefer not to say

What is the profession of this person?

$\square$ Pupil/in school

$\square$ Training/apprenticeship

University student

$\square$ Employee- Full time

$\square$ Employee- Part time

Civil servant

$\square$ Self-employed

$\square$ Unemployed/seeking employment Other 
Is a clinical diagnosis on the Autism Spectrum known for this person?
Yes
Suspected
No

\title{
I am giving detailed information about...
}

\author{
Myself \\ Child A- with Autism \\ Child B- without Autism \\ Other sibling \\ Other parent \\ Other household member
}

The person is...
female
male
other
prefer not to say

What is the profession of this person?

Pupil/in school

$\square$ Training/apprenticeship

$\square$ University student

$\square$ Employee- Full time

$\square$ Employee- Part time

Civil servant

$\square$ Self-employed

$\square$ Unemployed/seeking employment Other 
Is a clinical diagnosis on the Autism Spectrum known for this person?
Yes
Suspected
No

\section{I am giving detailed information about...}

Myself

Child A- with Autism

Child B- without Autism

Other sibling

Other parent

Other household member

Age in full years

The person is...
female
male
other
prefer not to say

What is the profession of this person?

$\square$ Pupil/in school

$\square$ Training/apprenticeship

$\square$ University student

$\square$ Employee- Full time

$\square$ Employee- Part time

Civil servant

$\square$ Self-employed

$\square$ Unemployed/seeking employment Other 
Is a clinical diagnosis on the Autism Spectrum known for this person?
Yes
Suspected
No

\section{I am giving detailed information about...}

Myself

Child A- with Autism

Child B- without Autism

Other sibling

Other parent

Other household member

The person is...
female
male
other
prefer not to say

What is the profession of this person?

Pupil/in school

$\square$ Training/apprenticeship

$\square$ University student

$\square$ Employee- Full time

$\square$ Employee- Part time

Civil servant

$\square$ Self-employed

$\square$ Unemployed/seeking employment Other 
Is a clinical diagnosis on the Autism Spectrum known for this person?
Yes
Suspected
No

I am giving detailed information about...

Myself

Child A- with Autism

Child B- without Autism

Other sibling

Other parent

Other household member

Age in full years

The person is...

female

$\bigcirc$ male

other

prefer not to say

What is the profession of this person?

$\square$ Pupil/in school

$\square$ Training/apprenticeship

University student

$\square$ Employee- Full time

Employee- Part time

$\square$ Civil servant

$\square$ Self-employed

$\square$ Unemployed/seeking employment Other 
Is a clinical diagnosis on the Autism Spectrum known for this person?

Yes

Suspected

No

For Child A, please indicate the severity of impairment due to their Autism Spectrum condition.

requires little or no support

requires support

requires substantial support

requires very substantial support

Is Child A impaired in any other way?

yes (we would be very grateful if you could provide further information)

no

prefer not to say 
Please indicate how much the following questions apply to Child A. Please tick one option per question $\mathrm{AQ02}$

1. S/he often notices small sounds when others do not.

2. S/he usually concentrates more on the whole picture, rather than the small details.

3. In a social group, s/he can easily keep track of several different people's conversations.

4. S/he finds it easy to go back and forth between different activities.

5. S/he doesn't know how to keep a conversation going with his/her peers.

6. S/he is good at social chit-chat.

7. When s/he is read a story, s/he finds it difficult to work out the character's intentions or feelings.

8. When s/he was in preschool, s/he used to enjoy playing games involving pretending with other children

9. S/he finds it easy to work out what someone is thinking or feeling just by looking at their face

10. S/he finds it hard to make new friends

strongly strongly
agree

agree agree disagree disagree

Please indicate how much the following questions apply to Child B. Please tick one option per question $\mathrm{AQ03}$

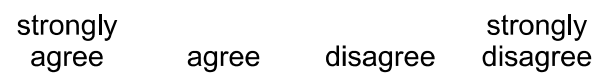

1. S/he often notices small sounds when others do not.

2. S/he usually concentrates more on the whole picture, rather than the small details.

3. In a social group, s/he can easily keep track of several different people's conversations.

4. S/he finds it easy to go back and forth between different activities.

5. S/he doesn't know how to keep a conversation going with his/her peers.

6. S/he is good at social chit-chat.

7. When s/he is read a story, s/he finds it difficult to work out the character's intentions or feelings.

8. When s/he was in preschool, s/he used to enjoy playing games involving pretending with other children

9. S/he finds it easy to work out what someone is thinking or feeling just by looking at their face

10. S/he finds it hard to make new friends 
What kind of accommodation do you live in?

flat

house

other

Do any household members live somewhere else some of the time?

No

Yes, please specify

O

Does your accommodation have direct access to the outside?

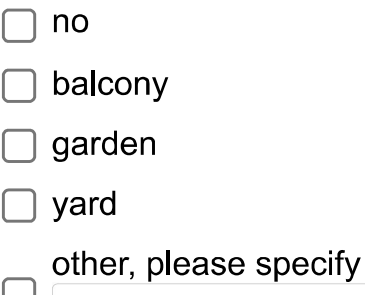

yard

other, please specify

How many bedrooms are there in your accommodation?
0
$\bigcirc 1$
$\bigcirc 2$
3
4
$\bigcirc 5$
6
$\bigcirc$
8
$\bigcirc$
10 or more

Is there a private room for each child in the household?

yes

no

unclear 
Please indicate the population size of your community.

less than one hundred

between one hundred and one thousand

between one thousand and ten thousand

between ten thousand and one hundred thousand

between one hundred thousand and one million

more than one million

Which is the country, you're currently living in?

Country:

Were you born where you are currently living?

yes, in this country and in this community / town

yes, in this country, but in a different community / town

in a different country

prefer not to say 
We are planning to circulate this survey in several different countries, so prease let us know about the situation where you live.

Where you live, did the current pandemic lead to the following administrative restrictions at any time?

CP15 $\square$

School closures

Complete lockdown

Where you live, are the following measures currently still in place?

School closures

Complete lockdown

Limits on groups of people

Limits on time and activities outside the house

Wearing protective clothing / face masks in public

Travel restrictions

Limits on sports and cultural activities

Restrictions for religious events

Restricted (non-corona) health-care and therapy options

Mandatory quarantine

Other (e.g., requirement / encouragement to carry tracking devices, documentation of purpose of visit or health status, ...)

What is your personal prediction about the future regarding the current crisis? When do you think the parruE I will be over?
1 month
3 months
6 months
1 year
several years
never 
In the following, we are interested in how children and adolescents on the Autism spectrum spend their day.

For each of the following activities, please estimate how much time Child A (i.e., the autistic person you AB55 reporting about) spent / spends on it in hours on a typical 24-hour day. Note, you can give proportions of the hour (e.g., $30 \mathrm{~min}=0.5$ ).

1. Use of digital devices (smartphone, tablet, laptop) for social communication (e.g. chatting with friend AC21 family).

Before corona restrictions

[Please choose] $\checkmark$

At the peak of the crisis

AC58

[Please choose] $\checkmark$

Currently

[Please choose] $\checkmark$

2. Use of digital devices (smartphone, tablet, laptop) for entertainment (e.g., games, films, surfing the WAC22 Before corona restrictions

[Please choose]

At the peak of the crisis

AC60

[Please choose] $\checkmark$

Currently

[Please choose]

3. Use of digital devices (smartphone, tablet, laptop) for education (e.g., homeschooling).

Before corona restrictions

[Please choose]

At the peak of the crisis

[Please choose] 
Currently

[Please choose]

4. Use of digital devices (smartphone, tablet, laptop) for - therapy, consultation, and coaching.

Before corona restrictions

[Please choose]

At the peak of the crisis

[Please choose]

Currently

AA89

[Please choose]

5. Special interests and hobbies.

Before corona restrictions

[Please choose]

At the peak of the crisis

[Please choose]

Currently

AA64 回

[Please choose]

6. Inside the house.

Before corona restrictions

[Please choose]

At the peak of the crisis

[Please choose]

Currently

AD03

[Please choose] 
7. In the garden or on the balcony.

Before corona restrictions

[Please choose]

At the peak of the crisis

AD08 回

[Please choose]

Currently

AD09 回

[Please choose]

8. Outside (but not in your own garden or on your own balcony).

AD13 回 Before corona restrictions

[Please choose]

At the peak of the crisis

AD14

[Please choose]

Currently

[Please choose]

9. Sleeping or in bed.

AD19

Before corona restrictions

[Please choose] $\checkmark$

At the peak of the crisis

AD20 回

[Please choose]

Currently

AD21 回

[Please choose] $\checkmark$ 
In the following, we are interested in how other children and adolescents speña their day.

For each of the following activities, please now estimate how much time Child B (i.e., the other child/addicsc ABrt you are reporting about) spent / spends on it in hours on a typical 24-hour day. Note again, you can give proportions of the hour (e.g., $30 \mathrm{~min}=0.5)$.

1. Use of digital devices (smartphone, tablet, laptop) for social communication (e.g. chatting with friend AC89 family).

Before corona restrictions

[Please choose]

At the peak of the crisis

AC90

[Please choose] $\checkmark$

Currently

AC91

[Please choose] $\checkmark$

2. Use of digital devices (smartphone, tablet, laptop) for entertainment (e.g., games, films, surfing the WADT: Before corona restrictions

[Please choose]

At the peak of the crisis

[Please choose] $\checkmark$

Currently

[Please choose]

3. Use of digital devices (smartphone, tablet, laptop) for education (e.g., homeschooling).

Before corona restrictions

[Please choose]

At the peak of the crisis

[Please choose] 
Currently

[Please choose]

4. Use of digital devices (smartphone, tablet, laptop) for - therapy, consultation, and coaching.

Before corona restrictions

[Please choose]

At the peak of the crisis

[Please choose]

Currently

AA70 回

[Please choose]

5. Special interests and hobbies.

Before corona restrictions

[Please choose]

At the peak of the crisis

[Please choose]

Currently

AA95

[Please choose]

6. Inside the house.

Before corona restrictions

[Please choose]

At the peak of the crisis

[Please choose]

Currently

[Please choose] 
7. In the garden or on the balcony.

Before corona restrictions

[Please choose] $\checkmark$

At the peak of the crisis

[Please choose]

Currently

[Please choose]

8. Outside (but not in your own garden or on your own balcony).

Before corona restrictions

[Please choose]

At the peak of the crisis

AD38

[Please choose]

Currently

[Please choose]

9. Sleeping or in bed.

AD43

Before corona restrictions

[Please choose]

At the peak of the crisis

AD44

[Please choose]

Currently

AD45 回

[Please choose] $\checkmark$

Page 15

HR

The next questions concern changes in the health and well-being of children and adolescents. 
Please rate the following aspects for Child A at the present moment in time, compared to the time befor current pandemic.

$\begin{array}{cccc}\text { much } & \text { slightly } & \text { slightly } & \text { much } \\ \text { decreased } & \text { decreased } & \text { similar } & \text { increased } \\ \text { increased }\end{array}$

General well-being

Adaptation abilities

Overall anxiety levels

Emotional reactions

Social behaviour

Please rate the following aspects for Child B at the present moment in time, compared to the time befor current pandemic.

$\begin{array}{cccc}\text { much } & \text { slightly } & \text { slightly } & \text { much } \\ \text { decreased } & \text { decreased }\end{array}$

General well-being

Adaptation abilities

Overall anxiety levels

Emotional reactions

Social behaviour 
Please indicate how Child A responds to the following pandemic hygiene routines.

Maintaining physical distance to other people $(1.5 \mathrm{~m})$

Regular hand-washing

Use of disinfectant

Wearing a face mask

Please indicate how Child B responds to the following pandemic hygiene routines.

Maintaining physical distance to other people $(1.5 \mathrm{~m})$ applicable negative neutral positive

Regular hand-washing

Use of disinfectant

Wearing a face mask 
PedsQL ${ }^{\text {TM }}$

Pediatric Quality of Life Inventory ${ }^{\mathrm{TM}}$

Version 4.0

\section{Parent Report for Children (ages 8-12)}

PedsQL ${ }^{\text {TM }}$ Copyright $@ 1998$ JW Varni, Ph.D. All rights reserved.

All original items of the PedSql are copyrighted. Therefore, we have only presented the parts that reflect our own instructions specific to this study.

You are now filling this in for Child A.

1.
$0-$
$1-$
2-
3-
4-

2.

0 -

1-

2-

3-

4- 
3.

0-

1-

- 2-

3-

4-

4.

0-

1-

2-

3-

4-

5.

0-

1-

- 2-

3-

4-

6.

$\mathrm{O}$

$\mathrm{O}$

0

0

0

7.

0-

1-

2-

3-

4- 
8.

$0-$

1-

2-

3-

4- 


\section{PedsQL ${ }^{T M}$}

\section{Pediatric Quality of Life Inventory ${ }^{T M}$}

\section{Version 4.0}

\section{Parent Report for Children (ages 8-12)}

PedsQL ${ }^{\text {TM }}$ Copyright $@ 1998$ JW Varni, Ph.D. All rights reserved.

1.

$0-$

- $1-$

- 2-

3-

4-

2.

0-

1-

- 2-

3-

4-

3.

0-

1-

2-

3-

4- 
4.

0-

$1-$

2-

3-

4-

5.

0

1-

2-

3-

4- 
PedsQL ${ }^{\text {TM }}$

Pediatric Quality of Life Inventory ${ }^{\mathrm{TM}}$

Version 4.0

\section{Parent Report for Children (ages 8-12)}

PedsQL $^{\mathrm{TM}}$ Copyright (c 1998 JW Varni, Ph.D. All rights reserved.
0 -
1-
2-
3-
4-

2.
0-
1-
2-
3-
4-

3.
0-
1-
2-
3-
4- 
4.
0-
1-
- 2-
3-
4-

5.

0-

1-

2-

3-

4-

Items related to the problems with school functioning:

1.

0

-1-

2-

3-

4-

2.

0-

-1-

2-

3-

4-

3.

0-

- 1-

- $2-$

3-

4- 
4.

0 -

1-

2-

3-

4-

5.

0

1-

2-

3-

4-

For any information on the use of the PedsQL ${ }^{\mathrm{TM}}$, please contact Mapi Research Trust, Lyon, France.

Internet: https://eprovide.mapi-trust.org 
PedsQL ${ }^{\text {TM }}$

Pediatric Quality of Life Inventory ${ }^{\mathrm{TM}}$

Version 4.0

Parent Report for Children (ages 8-12)

PedsQL ${ }^{\mathrm{TM}}$ Copyright $@ 1998$ JW Varni, Ph.D. All rights reserved.

You are now filling this in for Child B.

1.

0 -

1-

2-

3-

4-

2.

0 -

1-

2-

3-

4- 
3.

0-

1-

- 2-

3-

4-

4.

0-

1-

2-

3-

4-

5.

0-

1-

2-

3-

4-

6.

0 -

1-

- 2-

3-

4-

7.

0-

1-

2-

3-

4- 
8.

$0-$

1-

2-

3-

4- 
PedsQL ${ }^{\text {TM }}$

Pediatric Quality of Life Inventory ${ }^{\mathrm{TM}}$

Version 4.0

\section{Parent Report for Children (ages 8-12)}

PedsQL ${ }^{\text {TM }}$ Copyright $@ 1998$ JW Varni, Ph.D. All rights reserved.

1.
0-
1-
- 2-
3-
4-

2.
0-
1-
2-
3-
4-

3.
0-
1-
2-
3-
4- 
4.

0-

$1-$

2-

3-

4-

5.

0

1-

2-

3-

4- 
PedsQL ${ }^{\text {TM }}$

Pediatric Quality of Life Inventory ${ }^{\mathrm{TM}}$

Version 4.0

\section{Parent Report for Children (ages 8-12)}

PedsQL ${ }^{\mathrm{TM}}$ Copyright $@ 1998$ JW Varni, Ph.D. All rights reserved.

1.
0-
1-
- 2-
3-
4-

2.
0-
1-
2-
3-
4-

3.
0-
1-
2-
3-
4- 
4.

0 -

1-

2-

3-

4-

5.

$0-$

1-

2-

3-

4-

Items related to the problems with school functioning:

1.

0-

1-

2-

3-

4-

2.

0-

-1-

2-

3-

4-

3.

0-

- 1-

2-

3-

4- 
4.
0-
1-
- 2-
3-
4-

5.

For any information on the use of the PedsQL ${ }^{\mathrm{TM}}$, please contact Mapi Research Trust, Lyon, France.

Internet: https://eprovide.mapi-trust.org

Now please let us know how the current pandemic affected your entire family or household.

Please rate the following aspects for your family at the present moment in time, compared to the time beF02 可 current pandemic.

$\begin{array}{cccc}\text { much } & \text { slightly } & \text { slighlty } & \text { much } \\ \text { decreased } & \text { decreased } & \text { similar } & \text { increased }\end{array}$ increased

Overall stress levels

Regular daily structure

Conflict

Time spent together

Emotional closeness 
During the current pandemic did you receive any form of support through the following people or instit ST01 Please indicate all that apply.

\section{Support by....}

Close family

$\square$ Extended family and friends

$\square$ Neighbours

$\square$ Institutions

$\square$ Health service

Government

Which (if any) forms of support did you find particularly useful and why?

Close family, because...

Extended family and friends, because...

Neighbours, because...

Institutions, because ...

Health service, because...

Government, because...

(How) did the current pandemic affect your child's ASD-specific educational and therapy/ rehabilitation activities? 
This is the open answer box that allows you to tell us about other aspects or IIII pandemic that were important to you.

\section{Thank you for completing this questionnaire!}

We would like to thank you very much for helping us.

Your answers were transmitted, you may close the browser window or tab now. 